\title{
Hunger, nutrition, and precipitation: evidence from Ghana and Bangladesh
}

\section{Matthew Cooper ${ }^{1,2}$ (D) Molly E. Brown ${ }^{1} \cdot$ Carlo Azzarri $^{3} \cdot$ Ruth Meinzen-Dick $^{3}$}

Published online: 14 November 2019

(C) The Author(s) 2019

\begin{abstract}
Changing precipitation patterns caused by climate change are expected to have major impacts on food security and nutrition in agrarian areas in developing countries. However, the linkages between the duration and severity of precipitation shocks and their effects on child nutrition and household food security metrics remain underexplored. In this study, we used Feed the Future datasets from Ghana and Bangladesh to examine the impact of precipitation extremes on nutrition, measured by children's height-for-age and weight-for-height Z-scores, and food security, measured by the Household Hunger Scale. We used a spatial error regression to control for the effects of spatial autocorrelation, and we found an association between precipitation shocks and household hunger in both Ghana and Bangladesh, as well as an association between higher rainfall and worse child nutrition in Ghana.
\end{abstract}

Keywords Climate change $\cdot$ Precipitation · Food security $\cdot$ Hunger $\cdot$ Nutrition $\cdot$ Spatial error regression

\section{Introduction}

The Intergovernmental Panel on Climate Change (IPCC) states in the Fifth Assessment Report with high confidence that climate change will increase the risk of food insecurity through impacts such as droughts, flooding, and shifting precipitation patterns (IPCC 2013). While rates of undernutrition and food insecurity have been falling overall for the past few decades, there have been recent increases in these statistics in

Matthew Cooper

mattcoop@terpmail.umd.edu

1 Department of Geographical Sciences, University of Maryland, 2181 Samuel J. LeFrak Hall, 7251

Preinkert Drive, College Park, MD 20742, USA

2 International Institute for Applied Systems Analysis (IIASA) - Schlossplatz, 1 - A-2361, Laxenburg, Austria

3 International Food Policy Research Institute, 1201 Eye St NW, Washington, DC 20005-3915, USA 
some locations, which is somewhat attributable to climate shocks (FAO et al. 2018). Currently, the world is not on track to meet nutrition targets such as the second Sustainable Development Goal of zero hunger by 2030 (IFPRI 2016), and meeting these targets will require significant investments in climate-resilient agriculture and supply chains (WBG 2016). While increasing precipitation extremes induced by climate change are broadly known to be a threat to food security and nutrition, the interacting effects of rainfall shocks at various temporal scales, overall changes in precipitation patterns, and the current water requirements of livelihood systems are underexplored. Furthermore, much of the work that has been done has not sufficiently controlled for the effects of spatial autocorrelation in the patterns of precipitation shocks as well as in food security and nutrition outcomes. Thus, we here explore these interrelationships, taking care to account for spatial autocorrelation.

\section{Background and previous literature}

Substantial literature exists on the pathways by which precipitation shocks can affect food security (C. Funk et al. 2008; Lobell et al. 2008), with smallholder and subsistence farmers being particularly vulnerable (Morton 2007). The most immediate impact of unusually low or high rainfall levels on food security is through harming yields, decreasing the overall food availability in a location (Afifi et al. 2014; Hanjra and Qureshi 2010; Schlenker and Lobell 2010; Thornton et al. 2009). Subsistence farmers in low-income countries often plant crops that are adapted to local long-term rainfall patterns (Altieri et al. 2012; Altieri and Nicholls 2017), but when a given season has rainfall levels that are far from long-term norms, yields can suffer (Amikuzino and Donkoh 2012; Di Falco and Chavas 2015). Insufficient water decreases the overall crop productivity, while at the same time, overabundant water can delay planting, prevent waterlogged roots from absorbing nutrients, increase the presence of crop pests, and increase lodging, rot, and spoilage in harvests (Alam et al. 2011; Mirza 2011; Tefera 2012). In addition to harming the yields of grain and vegetable crops, rainfall shocks can affect the abundance of grazing areas, leading to lower availability of animal protein (Barrett and Santos 2014; Patton et al. 2007). A decrease in food availability can then cascade to constraints in food access: when yields and livestock productivity decrease, food prices increase, making food access difficult for poor households (Brown and Kshirsagar 2015; Devereux 2007; Sen 1983; Webb 2010). At the same time, households that rely on sales of agricultural products can experience decreasing incomes, while those relying on agricultural wage labor or trading with farmers can also be negatively affected (Bola et al. 2014; Cunguara et al. 2011; Kazianga and Udry 2006; Pandey et al. 2007; Udmale et al. 2015). Finally, excessive rainfall can increase the risk of infectious diseases such as malarial, parasitic, and diarrheal disease, in turn harming proper food utilization and increasing rates of undernutrition (Delpla et al. 2009; Paterson and Lima 2010). To deal with such shocks, households often adopt strategies of livelihood and agricultural diversification to protect their income and food security from these shocks (Lay et al. 2009; Maxwell 2002; Scoones 1998), while in some areas, government social protection programs and international aid can also provide relief (Calow et al. 2010; Haile 2005; Wilhite et al. 2014).

A recent review paper of research on precipitation and child undernutrition noted that there is "limited comprehensive empirical evidence at the household level" of an 
association (Phalkey et al. 2015). While it is broadly known that climate change will affect precipitation patterns and food security, much work remains to be done to understand which types of precipitation impacts will affect food security and which populations are most vulnerable. Several studies have found linkages between mean annual precipitation and child anthropometry (Akresh et al. 2011; Grace et al. 2012; Huss-Ashmore and Curry 1994), suggesting that changing precipitation patterns induced by climate change may affect child nutrition outcomes. Other researchers have focused on deviations from long-term norms and have found that both droughts and periods of excessive rainfall can impact child nutrition due to the effects of these precipitation extremes on agricultural production and overall food availability (Alderman 2010; Chotard et al. 2011; Rodriguez-Llanes et al. 2011). However, there is much disagreement about the timescales at which precipitation shocks are most relevant to child undernutrition, with some studies focusing on early-life rainfall (Alderman 2010; Rodriguez-Llanes et al. 2011), others focusing on prenatal precipitation (Woldehanna and Lives 2010), others testing for rainfall shocks in recent seasons (Skoufias and Vinha 2012), and still others looking at rainfall extremes during any single year in an individual's first 5 years of life (Alderman 2010). Overall, it seems that little work to date has examined how precipitation extremes at multiple time scales relate to child anthropometry outcomes. The relationship between the timing of precipitation impacts and levels of child stunting is complicated by the fact that while the first thousand days of a child's life are most critical for anthropometric attainment (Black et al. 2013a; du Plessis et al. 2016), there is a well-established phenomenon of catch-up growth, whereby a child can experience accelerated linear growth after the cessation of a nutritional shock (Behrman 2015; Godoy et al. 2010; Stobaugh et al. 2018; Wit and Boersma 2002). Thus, the linkages between the timing and duration of rainfall shocks and their impact on food security and nutrition merit further study.

While child anthropometry has been used as a metric of food security for decades, some researchers have raised important concerns regarding its lack of information on qualitative aspects of food insecurity (Coates et al. 2003; S. Maxwell 1996), and the fact that is a lagged signal of previous household food insecurity (Carletto et al. 2013). For these reasons, a number of new rapid indicators of food security have been developed, including the Household Hunger Scale (HHS) (Jones et al. 2013). However, linkages between these newer household food security metrics and climate and precipitation shocks, as well as their performance in relation to traditional child anthropometry metrics, remain underexplored.

We begin to address these questions by using geospatial data on precipitation patterns, population densities, and irrigation infrastructure in combination with the US Agency for International Development (USAID) Feed the Future (FTF) household survey data. These surveys were commissioned by the USAID and conducted by the International Food Policy Research Institute (IFPRI) in Bangladesh and the Monitoring, Evaluation and Technical Support Services (METSS) team in Ghana. By comparing surveys from both Bangladesh and Ghana, we have the opportunity to compare the response of HAZ, WHZ, and HHS scores to precipitation extremes in two very different agro-ecological contexts: in Bangladesh, with high annual precipitation and high levels of irrigation, as well as in northern Ghana, with low annual precipitation and no large-scale irrigation. These surveys were designed to measure food security and child nutrition as well as critical covariates such as household wealth and demographics 
(Feed The Future 2011). Additionally, some FTF surveys collected GPS points at each household, facilitating the extraction of meteorological data at the location of each household to explore relationships between household characteristics, precipitation conditions, and nutrition and food security outcomes (Brown et al. 2014). We utilized geolocated FTF surveys from Ghana (2012) and Bangladesh $(2011,2015)$ to test for an observable impact of rainfall levels and rainfall extremes on household food security, measured by the HHS, and child undernutrition, measured by child height-for-age Zscores (HAZ) and weight-for-height Z-scores (WHZ) using spatial error regression (SER) where necessary to account for possible spatial autocorrelation in the regressions.

\section{Data}

\section{Sources}

For this analysis, we used data on rural households from Feed the Future surveys conducted in Ghana and Bangladesh, taking care to properly account for effects of spatial autocorrelation (see "Modeling methods" section). The 2012 survey from Ghana was targeted at the Feed the Future Zone of Influence (ZOI) in the northern part of the country where Feed the Future interventions had taken place, while the survey from Bangladesh was a nationally representative panel survey from the years 2011 and 2015. In Ghana, enumeration areas (EAs) were established in the ZOI in the Upper West, Upper East, and Northern regions, as well as in parts of the Brong-Ahafo region. Households were randomly sampled from these EAs, and sampling weights were generated to make the data representative of the ZOI. In Bangladesh, households were selected from 325 primary sampling units (PSUs) throughout the country, and sampling weights were devised based on population census data to make the survey nationally representative.

Rural households with less access to high-quality roads and food markets generally have lower agricultural productivity (Stifel and Minten 2008). Thus, children in such areas are more affected by local precipitation patterns (Mulmi et al. 2016; Shively 2017) and typically exhibit higher rates of stunting (Thapa and Shively 2018). Therefore, we focused our analysis on rural households, as other researchers have done in similar studies (Phalkey et al. 2015). For Ghana, we only use data on households from PSUs designated as rural in the sampling frame of the Ghana survey, while for Bangladesh, because EAs were not classified into urban and rural, we excluded households within 30-min travel time to cities of over 20,000 people, with the time to travel to cities calculated using a methodology developed by IFPRI (Guo and Cox 2014). This yielded a final dataset of 2362 Ghanaian households and 4,878 unique Bangladeshi households. Of the Bangladeshi households, 4464 were observed twice, 342 where only observed in 2011, and 72 were only observed in 2015, yielding a dataset of 9342 observations. Finally, for our analysis of HAZ and WHZ scores, we had a final dataset of 3271 children from Bangladesh and 1346 children from Ghana. There were fewer children than households in both countries because not all households had children under 5 years old. 


\section{Outcome variables}

Our anthropometric outcome variables were height-for-age Z-scores (HAZ) and weight-for-height $\mathrm{Z}$-scores $(\mathrm{WHZ})^{1}$ of children under 5 years old. This approach involves comparing the height and weight/height ratio of a child under 5 years old to the distributions of these measurements for children of the same age and gender in a healthy population and assigning a Z-score (WHO 1995). A child's HAZ score is a common indicator of stunting, which results from long-term, chronic undernutrition, while a child's WHZ score is an indicator wasting, which results from recent and acute undernutrition (Lewit and Kerrebrock 1997). These metrics have been used for decades and have been found to be a salient indicator of child health status (Black et al. 2013b), and strongly related to agricultural variables (Bezner Kerr et al. 2011; Cunningham et al. 2015; Shively 2017; Webb and Kennedy 2014), environmental variables (Akseer et al. 2018; Buttenheim 2008; Chagomoka et al. 2018; Grace et al. 2017), as well as other child health metrics (Black et al. 2008; Caulfield et al. 2006; Dewey and Begum 2011). The population-level rates of stunting and wasting can be derived from the percentage of children with HAZ and WHZ scores less than -2 , although natural variation in human height as well as the arbitrary cutoff of -2 makes it inappropriate to classify an individual child as stunted or wasted from anthropometry alone (Perumal et al. 2018). Stunting and wasting can bear long-term effects on educational outcomes, disease risk, and potential adult income (Badham and Sweet 2010; Dewey and Begum 2011), and so reducing the rates of these indicators of undernutrition is a critical part of sustainable development (Daelmans et al. 2017).

In addition to child HAZ and WHZ scores, we also analyzed the Household Hunger Scale (HHS), a common indicator of household food insecurity (Jones et al. 2013), measured in both the Ghana and Bangladesh surveys. The HHS consists of three questions about a household's experience of insecurity (Ballard 2011), expressed by:

1. Was there ever no food to eat of any kind in your house because of lack of resources to get food?

2. Did you or any household member go to sleep at night hungry because there was not enough food?

3. Did you or any household member go a whole day and night without eating anything because there was not enough food?

Households report how frequently they had experienced these events over the previous 4 weeks, and a score is given for each question (never, 0 ; rarely or sometimes, 1; often, 2 ). The frequency scores across all three questions are summed to yield the final HHS score, with a value of 0 indicating no experiences of hunger, and a value of 6 indicating frequent experiences of all three forms of hunger over the previous 4 weeks. The HHS was developed from applications of the Household Food Insecurity Access Scale (HFIAS), which consisted of nine questions (Deitchler et al. 2010). Both the HHS and the HFIAS grew out of a recognized need for indicators of food security that could

\footnotetext{
${ }^{1}$ Height-for-age and weight-for-height Z-scores are expressed by: Z-zscore ${ }_{i}=\frac{x_{i}-\mu}{S D}$, where $x_{i}$ is the observed value of the anthropometric measure while $\mu$ is the median and $S D$ the standard deviation of the reference population's value (by age and gender), based on the WHO Child Growth Standards (2006).
} 
be rapidly deployed and that capture experiential aspects of food insecurity (Carletto et al. 2013; Coates et al. 2003). However, some of the nine questions in the HFIAS were found to be difficult to translate into other languages, while the item-step severity of the scale did not always change monotonically (Deitchler et al. 2010; Jones et al. 2013). Thus, the HHS is based on only three questions from the HFIAS which are most readily translatable and applicable to other cultural settings and are most likely to show item-step severity trends that are monotonic. Overall, compared to the HFIAS, the HHS is recognized to have the highest potential to be internally, externally and crossculturally valid (Deitchler et al. 2010). While it has been pointed out that the HHS measures hunger and not food security per se (Jones et al. 2013), food security itself cannot be measured directly (Vaitla et al. 2017) and the HHS certainly captures an important aspect of food security. Thus, in this paper, we take increased hunger as measured by the HHS score as indicative of worse food security.

\section{Predictor variables}

We used rainfall data from the Climate Hazards Group InfraRed Precipitation with Station (CHIRPS) dataset (Chris Funk et al. 2015), and we calculated the long-term rainfall norm as well as the standardized precipitation index (SPI) at intervals from 1 to 5 years for each household. The SPI is a derived measure of wetness/dryness for a given location based on long-term norms at that site, with a positive SPI score indicating a wetter-than-normal period and a negative SPI score indicating a drier-than-normal period (Table 1) (Guttman 1999). The time scale used to calculate the SPI varies depending upon the application, with studies focusing on agriculture using SPI a shorter timescales of up to 12 months (Brown 2008), studies focusing on WHZ scores calculating SPI over shorter windows such as 3 months (Delbiso et al. 2017; Lazzaroni and Wagner 2016), and studies focusing on other health impacts calculating SPI over longer windows of up to 48 months (Dinkelman 2017; Hyland and Russ 2019), with most studies finding a significant association between SPI and various outcome variables of interest.

To explore how rainfall aberrations over different time periods can affect food security and nutrition, for our analysis, we ran separate regressions with SPI values measured at 12-, 24-, 36-, 48-, and 60-month intervals for each country and outcome variable. For each survey analyzed, spatial variation in SPI scores is substantial. The maps in Fig. 1 show the observed 48-month SPI values in the Ghana and Bangladesh household surveys. In Ghana, precipitation in the north was slightly higher than normal, and near the Volta Basin in the east it was significantly wetter than normal. Bangladesh had showed similar rainfall patterns in the north in both 2011 and 2015, with households in north and central Bangladesh experiencing drier-than-average periods, with farmers in the northeast of the country in the Sylhet region experiencing wetter-thanaverage periods. In the south of Bangladesh, precipitation patterns differed between 2011 and 2015. Households in Barisal were experiencing ample rainfall in 2011 but experienced a dry period leading up to 2015, while households in Chittagong in the southeast experienced a mildly wet period in 2011 and a very wet period in 2015 . 


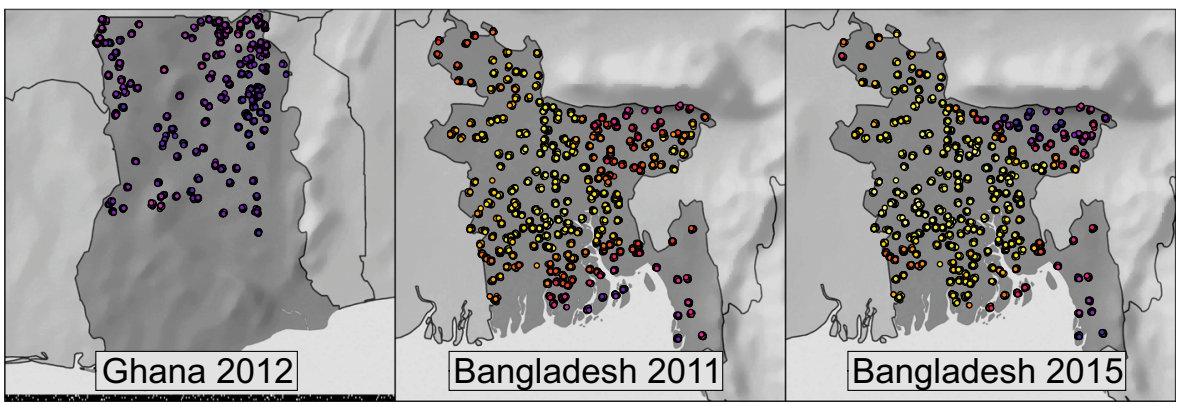

48-Month Standardized Precipitation-Evapotranspiration Index (SPEI)

$\begin{array}{llllllllll}2.3 & 1.8 & 1.3 & 0.8 & 0.3 & -0.2 & -0.7 & -1.2 & -1.7 & -2.2\end{array}$

Fig. 1 Locations of households used in the analysis, as well as observed 48-month SPI values at each household. Figure was made using ArcMap

\section{Control variables}

To better assess the relationship between precipitation and food security and nutrition, we control for several other geographic-, household-, and individual-level variables. Household wealth is a strong determinant of both household food security status and child nutrition status (Ahmed et al. 2012). Because there was no measure of income or expenditure in the surveys, we constructed an index of household wealth through principal component analysis (PCA) on household assets and other indicators of wealth (Vyas and Kumaranayake 2006). For each country, the first principal component factor explained a large proportion of the variance $(68 \%$ and $65 \%$ of the variance in Bangladesh and Ghana, respectively). The assets we used varied by country and are summarized in Appendix 1.

In addition to an asset index, other variables included were the household size, household head characteristics such as sex, religion, and education, as well as the fraction of a household not of working age. The two datasets did not have identical information on household or individual characteristics, and in some cases, variables were frequently missing or incomplete, so different control variables were used in the country-level analyses. In Bangladesh, the interview month was included in the

Table 1 SPI values and their interpretation. SPI values can be calculated over a range of timescales and are a measure of how rainfall levels over a given period differ from the long-term norm

\begin{tabular}{ll}
\hline SPI range & Interpretation \\
\hline$<-2$ & Extremely dry \\
-1.5 to -2 & Moderately dry \\
-1 to -1.5 & Dry \\
-1 to 1 & Normal precipitation \\
$1-1.5$ & Wet \\
$1.5-2$ & Moderately wet \\
$>2$ & Extremely wet \\
\hline
\end{tabular}


regressions in order to control for seasonal effects; however, these were not included in Ghana as the entire survey took place over the course of a month. These variables are summarized in Table 2.

In addition to household- and individual-level characteristics, we also included the population density of a location in the regressions, as well as a fixed effect at the Admin1 level, which corresponds to the region in Ghana and the division in Bangladesh. For population density, we used the World Pop dataset (Tatem 2017) and counted the number of individuals within $7.5 \mathrm{~km}$ of a given household. Because this information is available for 5-year intervals, we used population estimates for 2010 for FTF surveys conducted in 2011 and 2012; and estimates for 2015 for surveys conducted in 2015.

Finally, for Bangladesh, we included a term for the prevalence of irrigation around a household. This is because a large share of the county's agriculture is irrigated: in 2015, 71\% of the country's arable land was equipped with irrigation (FAOSTAT 2018). Furthermore, because irrigated agriculture does not depend on rainfall, irrigation systems can buffer food security and nutrition from the effects of local drought (Alam 2015), and can also provide protection against flooding (Alexander et al. 1998). Our metric of irrigation prevalence was the percent of the irrigated area out of the total rice cultivated area, derived

Table 2 Summary of variables included as covariates in the regressions as well as their availability by country. Where applicable, variable units are given

\begin{tabular}{lll}
\hline Variable & Ghana & Bangladesh \\
\hline Outcome variables & & \\
Household Hunger Scale & Yes & Yes \\
Height-for-age Z-Score & Yes & Yes \\
Geographic variables & & \\
Population within 7.5 km (count of people) & Yes & Yes \\
Percent of agricultural area irrigated & No & Yes \\
Household variables & & \\
HH size (number of individuals) & Yes & Yes \\
Asset index & Yes & Yes \\
HH head religion & Yes & Yes \\
HH head age (years) & Yes & Yes \\
HH head literate & Yes & Yes \\
HH head education level & No & Yes \\
HH head sex & Yes & Yes \\
Percentage of household under 12 or over 60 years of age & Yes & Yes \\
Interview month & No & Yes \\
Survey year & n.a. & Yes \\
Individual variables (used in nutrition analyses) & & \\
Age (months) & Yes & Yes \\
Gender & Yes & Yes \\
Child's birth order & Yes & No \\
Siblings born within 24 months & Yes & No \\
\hline & & \\
\hline
\end{tabular}


from the MapSPAM model (You et al. 2014), which is in turn based on FAO's Global Map of Irrigation Areas (GMIA) (Siebert et al. 2013), and is at a resolution of $10 \mathrm{~km}$. We use a metric for the irrigation in areas around a household rather than a household's specific levels of irrigated agriculture because many households, especially poorer households, rely on agricultural labor on other's farms for their income. Thus, a household's income would not only be affected by whether their own fields are irrigated but also the presence of irrigated agriculture within a few kilometers.

\section{Descriptive statistics}

To generate hypotheses to be tested in the multivariate regression framework and facilitate the interpretation of estimation results, in this section, we graph probability density and probability mass functions, as well as summary statistics of several key statistics in the regressions. Additionally, complete summary statistics are provided in Appendix 2.

\section{SPI}

For each country, the SPI values provided ample variation in each regression (Fig. 2). SPI scores in Bangladesh varied more than in Ghana, often from less than - 2, signaling extremely dry conditions, to 2 , signaling moderately wet conditions, depending on the period. In both 2011 and 2015, the majority of households were subject to lower rainfall than the long-term norm for SPI values calculated at all time windows. For Ghana, none of the households experienced drought at the time of the survey, and only a few households had SPI values less than 0 when calculated by the 12-month window, meaning that we can only examine the effects of extreme rainfall on food security and anthropometry outcomes in Ghana and not the effects of drought. For most time windows, SPI values ranged from near-normal to moderately wet conditions.

\section{Average annual precipitation}

The density plots below report the distribution of average annual precipitation levels among households in the two countries. Bangladesh receives significantly more rainfall than Ghana,

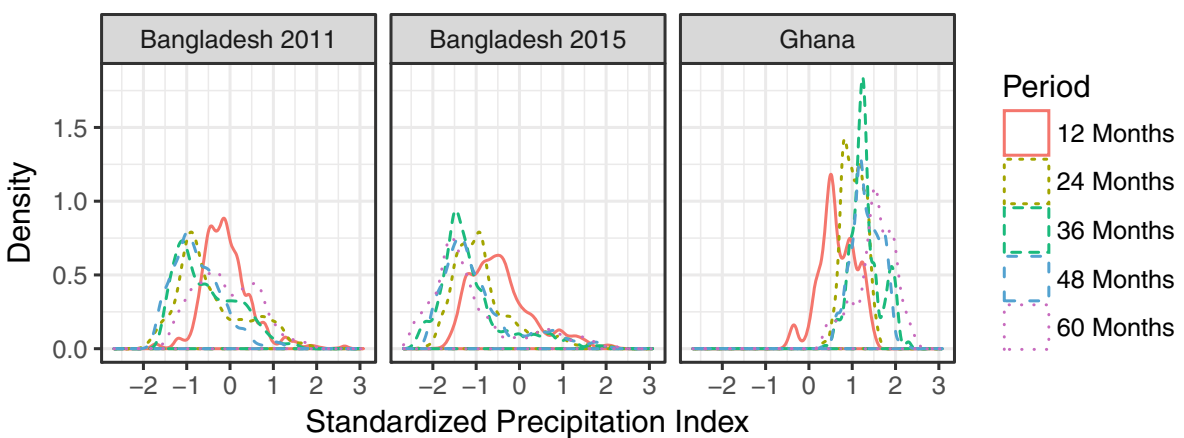

Fig. 2 Density plots of observed SPI scores, by survey and the period over which the SPI was calculated. Figure was made in R using the ggplot2 library 
with the minimum rainfall in Bangladesh being similar to the maximum rainfall in Ghana. Bangladesh shows much greater variation in rainfall distribution, from 1420 to $5000 \mathrm{~mm}$ per year, whereas Ghana only ranges from 912 to $1370 \mathrm{~mm}$ per year (Fig. 3).

\section{HHS}

In Bangladesh, $10.1 \%$ of households had experienced hunger in the previous 4 weeks at the time of the 2011 survey and $11.7 \%$ had experienced hunger in the previous 4 weeks at the time of the 2015 survey, with progressively fewer households at each level of increasing severity. Ghana, on the other hand, showed higher scores, with $56.7 \%$ households reporting some level of hunger (Fig. 4). The count and percent distribution of households for each value of the hunger scale is provided in Appendix 2.

\section{Child HAZ and WHZ scores}

Rates of stunting and were very high in both Ghana and Bangladesh, at $38 \%$ and $43 \%$, respectively, while rates of wasting were lower, at $14 \%$ in Bangladesh and $11 \%$ in Ghana. While the Z-scores of children clustered well below 0 in each country, there was still substantial variation in heights (Fig. 5).

\section{Modeling methods and results}

In this analysis, we took care to control for spatial autocorrelation. This is because outcomes such as HHS and HAZ scores are often correlated spatially: nearby households are likely to show similar nutrition and food security outcomes. The correlations in outcomes could be due to a variety of factors, such as spatial clustering in the distribution of poverty, disease burden, market access, soil fertility, pest outbreaks, or farming practices. Thus, it is necessary to use a SER because OLS assumes that each observation is independent. If there is an underlying spatial structure to the error terms, a simple ordinary least-squares (OLS) regression will tend to underestimate the variance and therefore will overestimate the $p$ values in the model (Ward and Gleditsch 2008).

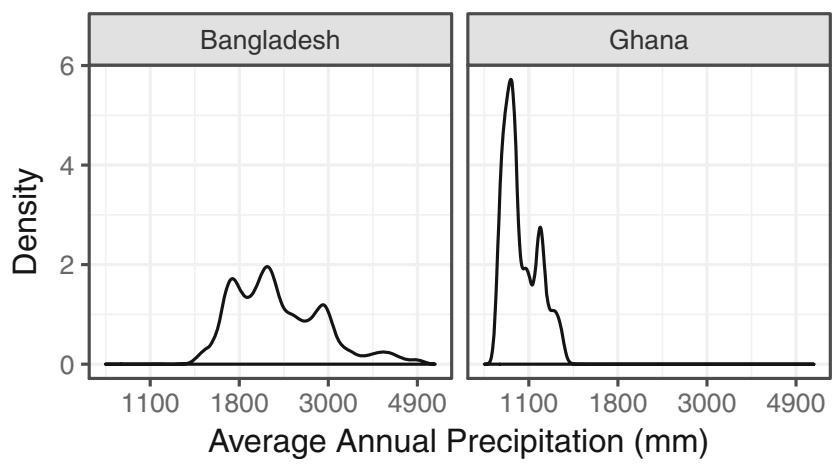

Fig. 3 Density plots of average annual precipitation levels across observed households, by country. Figure was made in R using the ggplot2 library 

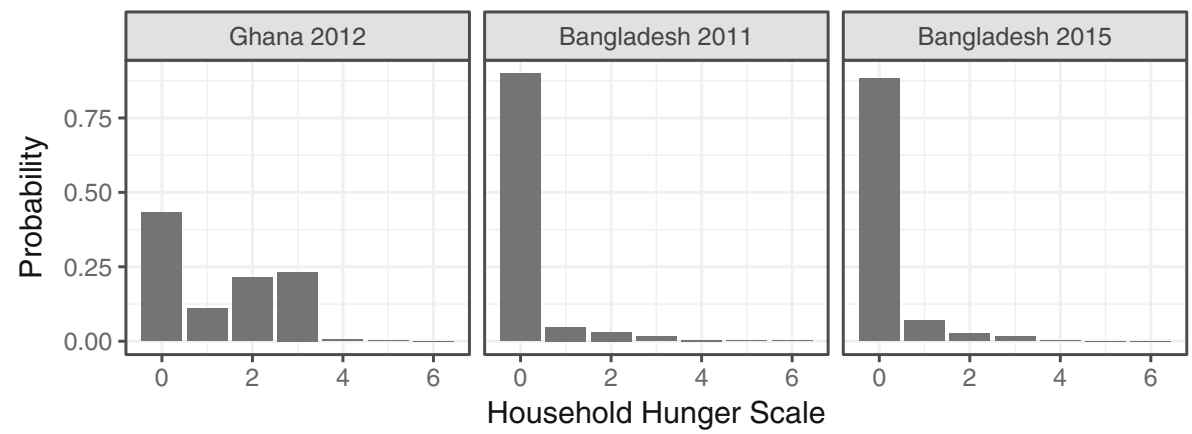

Fig. 4 Frequency plot of observed Household Hunger Scale (HHS) scores, by survey. Lower scores indicated less hunger

To verify that there is a need to conduct a SER and to determine the distance cutoffs for the spatial weight matrix, we first conducted an exploratory spatial data analysis (ESDA). For each outcome and each country, we tested to determine whether or not the residuals of an OLS regression show spatial autocorrelation, and we did this using a Moran's $I$ test (Table 3). Then, for outcomes for which spatial autocorrelation was detected by a Moran's I test, we plotted a correlogram for the outcome variable to determine the distance at which spatial autocorrelation disappears and then used this distance to construct a spatial weight matrix.

We modeled outcome variables for which we observed spatial autocorrelation using a SER, which uses a spatial weights matrix to correct the error term and obtained unbiased coefficients and $p$ value estimates (Anselin 2001; Bivand et al. 2005; Ward and Gleditsch 2008). The SER differs from the spatially lagged regression (SLR) model

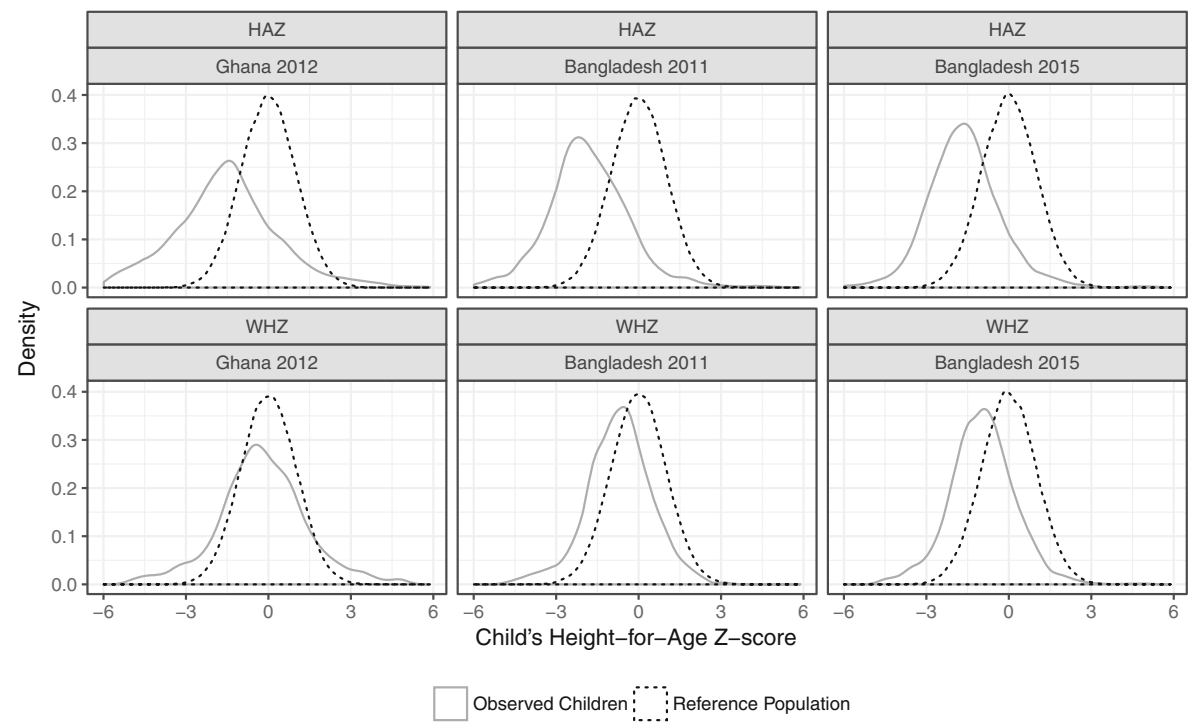

Fig. 5 Density plot of observed child height-for-age Z-scores (HAZ) and weight-for-age Z-scores in comparison to a reference healthy population, by country. An HAZ score of less than -2 is considered stunted and a WHZ score of less than -2 is considered wasted. Figure was made in R using the ggplot2 library 
Table 3 Results of a Moran's I test for spatial autocorrelation for WHZ, HAZ, and HHS residuals in Bangladesh and Ghana

\begin{tabular}{llllll}
\hline Country & Variables & Observed value & Expected value & Standard deviation & $P$ value \\
\hline Ghana & HAZ & 0.00247 & -0.00074 & 0.00549 & 0.559 \\
Ghana & WHZ & 0.00603 & -0.00074 & 0.00549 & 0.217 \\
Ghana & HHS & 0.0477 & -0.00042 & 0.00384 & 0 \\
Bangladesh & HAZ & 0.00887 & -0.00031 & 0.00236 & 0.000105 \\
Bangladesh & WHZ & 0.00496 & -0.00031 & 0.00236 & 0.0261 \\
Bangladesh & HHS & 0.00422 & -0.00011 & 0.000911 & 0.00000203 \\
\hline
\end{tabular}

in that it models spatial correlation in the error term due to unobservable processes affecting households across space, while the SLR explicitly models the spatial correlation in the dependent variable due to observable characteristics spatially correlated across households (Ward and Gleditsch 2008). A SLR is more appropriate when the value of one observation affects the value of nearby observations, whereas a SER is more appropriate when the values of observations are independent from each other but affected by unobservable underlying spatial processes. Since child nutrition and household food security statuses are more affected by unobserved spatial conditions than by the correlation of the observed characteristics among children and households across space, we used a SER.

Specifically, a SER takes the form:

$$
y=\beta_{0}+\boldsymbol{\beta} \boldsymbol{X}+\boldsymbol{\lambda} \boldsymbol{W} \boldsymbol{\xi}+\epsilon
$$

where, as in a typical regression, $y$ is the outcome variable, $\beta_{0}$ is the intercept, $\beta$ is a vector of coefficients, and $\boldsymbol{X}$ is a matrix of observed covariates. In a SER, the error term is decomposed into $\epsilon$, the spatially uncorrelated error component, and $\xi$, the spatial error component, which is estimated using the matrix of spatial connectivities Wand the parameter $\lambda$, which indicates the degree to which error terms are spatially correlated. We estimated the matrix of spatial connectivities $\boldsymbol{W}$ for neighbors within the cutoff distance determined by the correlograms. In every regression, we included sample weights.

For each country, we ran separate regressions for child WHZ, HAZ, and HHS scores across all 5 SPI windows and included the relevant covariates in each regression. Due to the number of hypothesis tested (30), we used a Bonferroni correction when testing for statistical significance of the coefficient of the SPI term to avoid the possibility of a type I error of incorrectly rejecting the null hypothesis, and hence, we use an alpha value of $\alpha=\frac{0.05}{30}=0.00167$. In the case of Bangladesh, given the availability of the panel dataset for HHS, we first conducted a Chow test to identify a possible structural change over time, in absence of which it would be appropriate to pool the two waves of data (Wooldrige 2013). The test statistic was not significant for any SPI value $(\alpha=$ 0.01 ), and there was no a priori reason to expect the effects of precipitation shocks on food security and nutrition to be different between 2011 and 2015, so we pooled the waves and included a fixed effect for the survey year. Parameter estimates and test statistics are presented in Appendix 3. 
Finally, while the outcome variable of the HHS is a series of discrete categories and would be ideally suited for an ordinal logit or probit regression, this functionality was not available in the spdep package of R (Bivand et al. 2005), which was used to estimate the regressions. Thus, we fit those regressions as if HHS were a continuous outcome variable. While this may not yield perfect estimates of the coefficients, our main interest is in the signs of the coefficients and their standard errors, and a comparison of aspatial ordered logit and OLS regressions shows that the signs of the coefficients are the same in almost all cases and that the t-scores are similar (Appendix 4). This suggests that the t-scores for a regression with the HHS as a continuous variable are roughly the same as t-scores for an ordered logit regression and that overstating the significance of a variable by treating the HHS as a continuous variable should not be an issue. Furthermore, the HHS has been validated to show consistency in item-step severity in most cases (Deitchler et al. 2010), suggesting that it may give reasonable coefficient estimates if treated as a continuous variable.

\section{ESDA}

We tested for spatial autocorrelation in our outcome variables as well as in the residuals of an OLS using a Moran's I test for each outcome variable and each country. This showed that there was spatial autocorrelation for the HHS score in Bangladesh and in Ghana, as well as for the HAZ and WHZ score in Bangladesh; however, there was no autocorrelation for HAZ or WHZ scores in Ghana.

For the three outcome variables for which there was spatial autocorrelation, we examined a correlogram to determine the distance at which autocorrelation persists (Fig. 6). The distance at which the $95 \%$ error bar dips below 0 is the distance at which a Moran's $I$ test no longer shows significant spatial autocorrelation. This showed that there was significant $(p<0.05)$ spatial autocorrelation to $80 \mathrm{~km}$ for the HHS score in Bangladesh, to $30 \mathrm{~km}$ for the HAZ score in Bangladesh, to $20 \mathrm{~km}$ for the WHZ score in Bangladesh, and to $125 \mathrm{~km}$ for the HHS score in Ghana. We used these distances to establish the cutoff distances in defining our spatial weights matrices for the SERs.

\section{Ghana}

Although we varied the SPI window from 1 to 5 years, the covariates remained mostly unchanged and had similar estimates across the regressions. The child's age was a

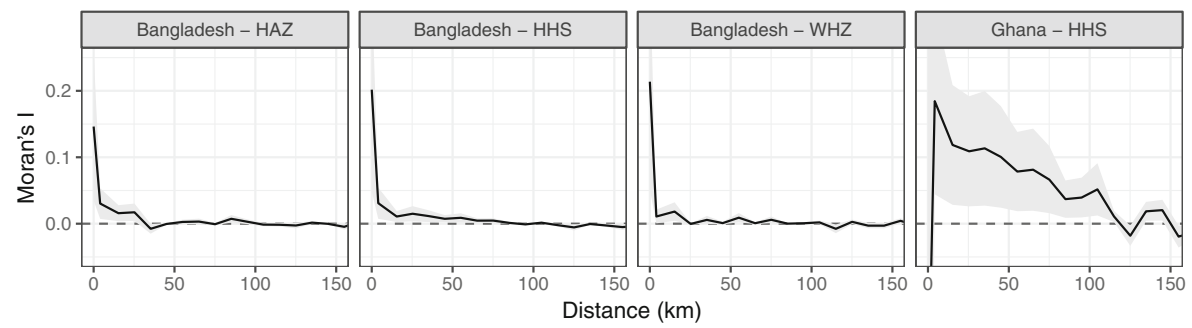

Fig. 6 Correlograms showing Moran's $I$ at various spatial lags, with a 95\% confidence interval shaded in gray. These estimates were used to create the spatial weights matrices used in the regressions 
significant predictor of the child's HAZ or WHZ score, with older children having lower HAZ scores but larger WHZ scores. Household size and household religion were significant predictors of HAZ scores, with larger households being associated with higher HAZ scores and households with no religion being associated with children with lower HAZ scores. Various regions were also significant as fixed effects for child WHZ scores. For HHS scores, significant covariates included the household size, household head age, whether the household head was literate, and the household religion. Additionally, the average annual precipitation was significant across many of the HHS regressions, with households receiving more annual precipitation being associated with less hunger.

For SPI values, excessive rainfall over a short time window of 12 months was associated with lower WHZ scores, whereas excessive rainfall over longer time windows of 36 months were associated with lower HAZ scores. Excessive rainfall over periods of 36 and 48 months were also associated with lower HHS scores (Fig. 7).

\section{Bangladesh}

Many of the covariates were significant in the Bangladesh regressions. Similar to Ghana, the child's age was significant for both HAZ and WHZ scores; however, in Bangladesh, older children had both lower HAZ and WHZ scores. Household head education had significant effects on both WHZ and HAZ scores, with more educated household heads being associated with better nourished children. The month of the household survey also had a significant effect on both HAZ and WHZ scores, especially for months earlier in the calendar year. For covariates of HHS, education played a significant role, with more educated household heads having lower HHS scores, indicating less hunger, and less-educated household heads having higher HHS scores, indicating more hunger. Other household demographic factors were also important, with households with a larger fraction of young and old having higher HHS scores, and

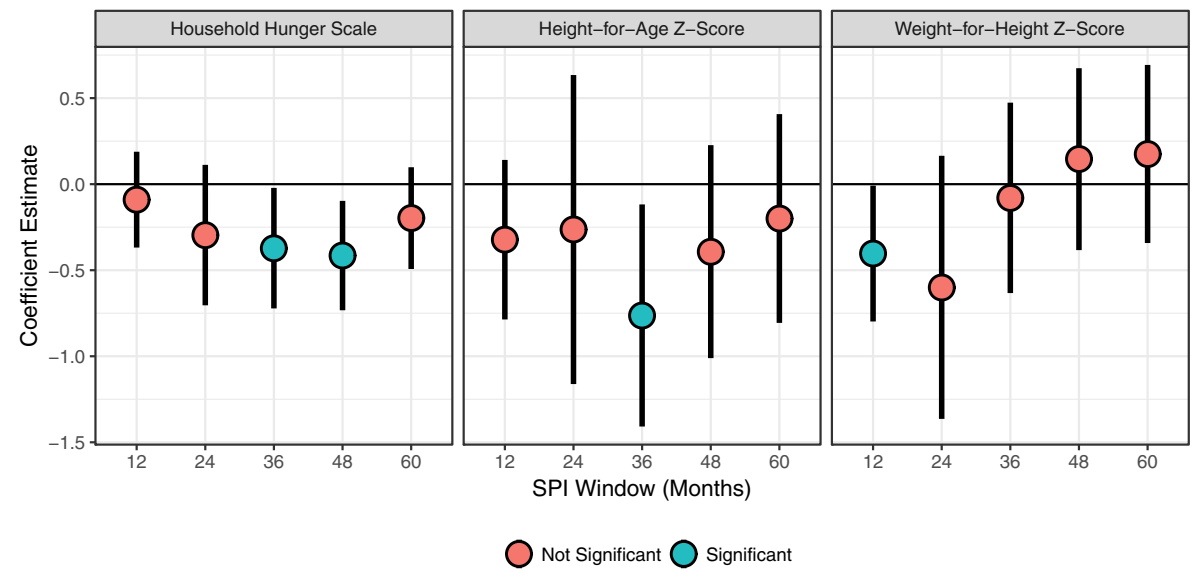

Fig. 7 Coefficient estimates for Ghana for SPI values calculated at varying windows. Error bars and significance values are shown after accounting for a Bonferroni correction. Note: while higher HAZ and WHZ scores indicate good nutrition, higher HHS scores indicate poor food security. Figure was made in R using the ggplot2 library 
larger households having lower scores. Many of the divisions of Bangladesh were also significant predictors of a household's HHS score. Finally, mean annual precipitation was never a significant predictor of a household's HHS score.

For nutrition and food security outcomes across all of the SPI time windows, the recent SPI was never a significant predictor of child nutrition outcomes like HAZ and WHZ. However, the 48-month SPI was a significant predictor of household hunger scores, with greater rainfall being associated with higher scores, indicating more hunger. None of the other time windows were significant predictors of hunger (Fig. 8).

\section{Discussion}

This study has contributed to the literature on precipitation shocks and food security and nutrition in three ways. First, it has demonstrated the utility of SER in accounting for geographic autocorrelation in food security outcomes. This type of model can reduce the impact of unobserved spatial processes that can confound results in a simple OLS regression. Such an approach is important for disentangling the effects of climate from other variables that also have a spatial component, such as wealth, market access, and livelihood systems. Secondly, this study has compared how shocks over various time periods may affect food security and nutrition outcomes in both an arid country as well as in a country with relatively high average rainfall. Finally, this study has examined how both anthropometric measures and the HHS response to precipitation shocks and demonstrates that the HHS is a useful and informative metric of studying household food security.

The distribution of both precipitation regimes and precipitation shocks have a spatial component—nearby households are likely to have similar precipitation patterns and experience similar precipitation shocks. Similarly, nearby households are likely to have similar levels of food security and nutrition, as these are affected by a variety of

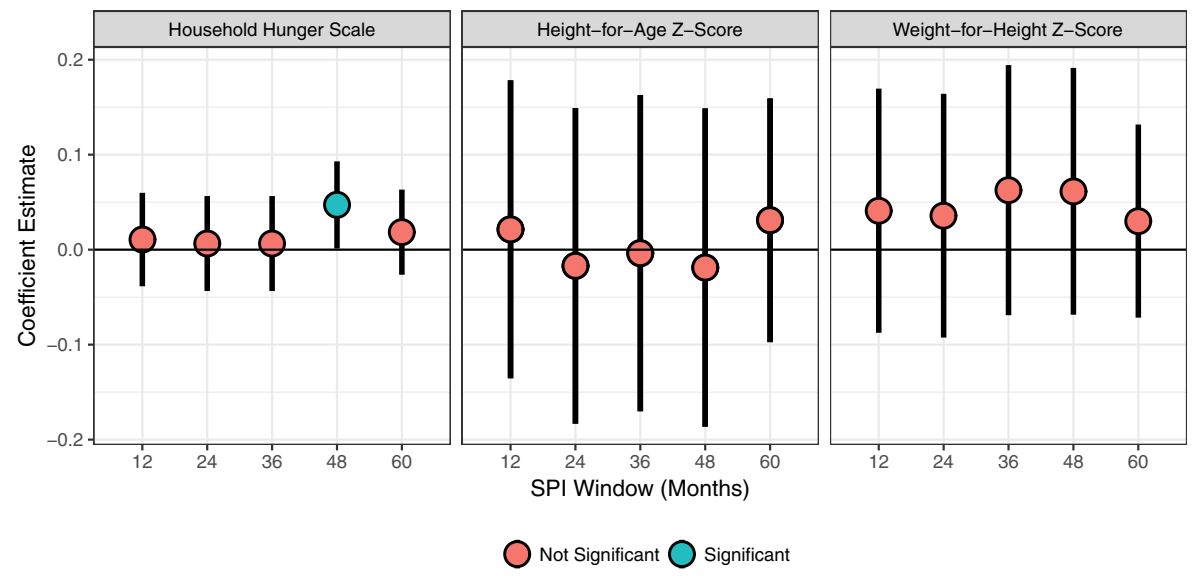

Fig. 8 Coefficient estimates for Bangladesh for SPI values calculated at varying windows. Error bars and significance values are shown after accounting for a Bonferroni correction. Note: while higher HAZ and WHZ scores indicate good nutrition, higher HHS scores indicate poor food security. Figure was made in R using the ggplot2 library 
underlying spatial processes such as the distribution of wealth, infrastructure, and livelihood systems. Thus, when assessing the relationship between precipitation patterns and food security outcomes, it is important to control for this autocorrelation to minimize the possibility of a type I error and incorrectly reject the null hypothesis. In this paper, we demonstrate this approach, beginning with an ESDA to identify for which regressions a SER is necessary.

Examining SPI calculated across different windows allowed us to compare how rainfall levels over different periods of time affected child nutrition and household food security. In Ghana, the response of WHZ and HAZ scores to different rainfall windows were in line with what the literature would suggest: short-term rainfall shocks over 12 months were significant predictors of WHZ scores, an indicator of short-term undernutrition, whereas longer periods of 36 months were significantly associated with HAZ scores, which indicate long-term, chronic undernutrition (Lewit and Kerrebrock 1997; WHO 1995). In both cases, increased rainfall was associated with worse nutrition outcomes. While HAZ and WHZ scores respond differently to rainfall shocks over different time periods, in both Ghana and Bangladesh, household hunger was affected by longer term processes. This suggests that most households will not experience food insecurity after a single poor crop season or even a year of poor yields. Rather, in the two countries examined, it is the compounding effects of multiple years of precipitation extremes that make households vulnerable to hunger. This indicates that some studies which have examined the impacts of short-term SPI on malnutrition would benefit from also examining SPI calculated over longer timescales (Delbiso et al. 2017; Lazzaroni and Wagner 2016). Finally, in Ghana, higher average annual precipitation levels were associated with lower household hunger scores, suggesting that there may be impacts on food security as areas experience gradual drying over multiannual and decadal periods, rather than just precipitation extremes over shorter periods.

By comparing Ghana and Bangladesh - two countries with similar levels of wealth per capita ${ }^{2}$ and large agrarian populations but starkly divergent precipitation regimeswe can get a better sense of what kind of precipitation shocks affect food security in which contexts. Overall, with regard to hunger, it seems that in arid Ghana, more rainfall improves food security, as decreased hunger was associated with both increased precipitation over 36- and 48-month windows as well as increased average annual precipitation. It is particularly noteworthy that all households in Ghana were observed during wet periods, and even exceptionally high precipitation levels were not associated with increased hunger. In contrast to Ghana, in Bangladesh, increased rainfall was associated with more hunger. This is not entirely surprising, given that flooding in Bangladesh has been associated with increased stunting and food insecurity (Del Ninno et al. 2003; Douglas 2009; Monirul Qader Mirza 2002). These findings indicate that precipitation shocks will not necessarily harm food security in all contexts. Rather, whether or not a shock affects food security is depended on prevailing agro-ecological conditions. In comparing Bangladesh and Ghana, results further indicate that food security and nutrition in northern Ghana may be more sensitive to rainfall deviations from long-term norms than Bangladesh is, as WHZ, HAZ, and HHS scores were affected by precipitation in Ghana, but only HHS scores were affected by precipitation

\footnotetext{
${ }^{2}$ According to the World Bank, in 2017 Ghana had a GDP per capita of \$1,641.49 while Bangladesh had a slightly lower GDP per capita of \$1,516.51 (The World Bank 2019)
} 
in Bangladesh. This may be due to the fact that Bangladesh has extensive irrigation infrastructure, making agricultural production less affected by local rainfall.

Another contribution of this study to the literature was the comparison of the HHS to child anthropometry. In Ghana, counterintuitively, greater rainfall was associated with less hunger but more undernutrition. Furthermore, the findings are more robust and less likely to be due to spurious correlation because we controlled for both spatial autocorrelation and testing multiple hypothesis by using a SER regression as well as a Bonferroni correction. These findings may be explained in part by the role that infectious disease can play in affecting child nutrition (Dowell 2001; Patz et al. 2004). Excess rainfall can lead to increased incidence of malaria (Briët et al. 2008; Odongo-Aginya et al. 2005; Thomson et al. 2005), parasite infections (McCreesh et al. 2015; Raso et al. 2006), diarrheal disease (Carlton et al. 2014), and other infectious diseases (Patz et al. 2005), especially cholera (Hashizume et al. 2008; Moore et al. 2017). These effects may be especially pronounced in areas without the appropriate infrastructure to handle large quantities of rainfall. Thus, it may be that increased rainfall has mixed results for food security, because while it can lead to more food production and agricultural income, it can also hamper food utilization due to an increased disease and parasite burden. These results reinforce the notion that climate change will have complex impacts on human well-being. Furthermore, these results echo previous findings that food security is complex and multidimensional, and is more accurately characterized by using multiple complementary metrics (Coates et al. 2003; Vaitla et al. 2017).

In Bangladesh, only the HHS was related to rainfall patterns, while both HAZ and WHZ scores were uncorrelated with recent rainfall aberrations, even though previous literature had found a relationship between high rainfall and stunting in that country (Rodriguez-Llanes et al. 2011). This may be somewhat due to the fact that the dataset used in the analysis has relatively few households with children under 5 years old (only $15 \%$ in Bangladesh in both 2011 and 2015), meaning that the regressions for HAZ and WHZ scores relied on datasets of significantly reduced size. Thus, the regressions with anthropometric outcomes had less statistical power for inference. These findings suggest that, while much previous literature has focused on the relationship between rainfall and child anthropometry (Cornwell and Inder 2015; Lopez-Carr et al. 2016; Maccini and Yang 2009; Rodriguez-Llanes et al. 2011), rapidly deployable metrics of food security at the household level such as the HHS may be more robust indicators of climate change impacts than just child anthropometry, especially as birth rates decline worldwide and households are less likely to have children under five present.

While this study made several contributions to the literature, there remain further avenues for research. For example, while we controlled for additive effects of irrigation in Bangladesh, future work could test for an interactive effect between irrigation levels and SPI. Furthermore, future studies could account for temperature, which has been shown to have a direct effect on child health outcomes (Grace et al. 2015) and also plays a significant role in intensifying the severity of drought on agriculture because it increases evapotranspiration (Beguería et al. 2014), although available temperature datasets are typically at coarser spatial and temporal scales than precipitation datasets (C. C. Funk et al. 2016; Sheffield et al. 2006). Thus, future work could potentially extend the SPI by using biogeophysical models to estimate local evapotranspiration and calculate the standardized precipitation-evapotranspiration index (SPEI) in contexts where temperature data is available. 


\section{Implications}

The present work has many implications for policymakers and researchers. We showcase the utility of SER and emphasize the importance of testing for spatial autocorrelation in analysis of factors that vary through space, such as food security and nutrition. Our study also highlights the utility of the HHS as tool to measure food security in addition to commonly used anthropometric metrics such as the child anthropometrics Z-scores. This is because we found diverging impacts of excessive of precipitation on anthropometry and household hunger in Ghana, as well as because we found the HHS to be more sensitive than child anthropometry to precipitation extremes in Bangladesh. These findings are indicative of the complex ways in which climate shocks can affect human well-being and highlight the importance of measuring multiple aspects of food security to get a comprehensive characterization of foods security. More research is needed on the HHS and similar rapid food security indicators, as policy tools such as the Integrated Food Security Phase Classification may benefit from incorporating such indicators (IPC/FAO 2015). Finally, we have presented evidence that both drought and periods of excessive rainfall are significantly correlated with food security outcomes, with dry areas potentially more vulnerable to drought and wetter areas potentially more vulnerable to excessive rainfall. To better understand the role that environmental and infrastructural context plays in moderating the impacts of precipitation shocks and food security and nutrition, more comparative and multinational studies are needed.

Acknowledgments We would like to thank Greg Seymour and Chris Gray for feedback on earlier drafts and insights on the Feed the Future datasets used in this study.

Funding information Open access funding provided by International Institute for Applied Systems Analysis (IIASA). This research was supported by a Gender, Climate Change and Nutrition Integration Initiative (GCAN) student award (RA No. 2017X264.COO) from the International Food Policy Research Institute (IFPRI) under the GCAN project directly supported by the US Agency for International Development (USAID), which is implemented under the CGIAR Research Program on Climate Change, Agriculture and Food Security (CCAFS). Computational resources in Azure were made available by a Microsoft AI for Earth grant.

\section{Appendix 1. Asset index variables}

\section{Ghana}

The asset index for Ghana included dwelling conditions; whether the house was rented, owned or borrowed; water treatment, source for light and fuel; garbage disposal; roof and walls material; type of toilet; and water sources, all variables reported in Module 9.

\section{Bangladesh}

The asset index for Bangladesh included the household's total land area cultivated, rented, owned; house ownership, number of rooms in the house; whether house had electricity; water source; toilet type; roof, walls, and floor material; number of cattle, poultry, sheet, goats, and other livestock owned; television, radio, motorbike, telephone, tractor, or cart plow ownership; and whether the household used organic or chemical fertilizer. 


\section{Appendix 2. Summary statistics}

Table 4 Child stunting

\begin{tabular}{|c|c|c|c|}
\hline & & Ghana & Bangladesh \\
\hline \multirow[t]{3}{*}{ Child's age (months) } & Max & 59 & 60 \\
\hline & Mean & 32.4 & 29 \\
\hline & Min & 7 & 0 \\
\hline \multirow[t]{2}{*}{ Child's sex (\%) } & Female & 49.6 & 49.1 \\
\hline & Male & 50.4 & 50.9 \\
\hline \multirow[t]{3}{*}{ Child's birth order } & $\operatorname{Max}$ & 18 & \\
\hline & Mean & 4.2 & \\
\hline & Min & 1 & \\
\hline \multirow[t]{3}{*}{ Number of siblings born within 24 months } & Max & 4 & \\
\hline & Mean & 0.4 & \\
\hline & Min & 0 & \\
\hline \multirow[t]{3}{*}{ Child's height-for-age Z-score } & Max & 5.5 & 5.9 \\
\hline & Mean & -1.5 & -1.7 \\
\hline & Min & -6 & -5.9 \\
\hline \multirow[t]{3}{*}{ Child's weight-for-age Z-score } & Max & 4.9 & 4.9 \\
\hline & Mean & -0.2 & -0.8 \\
\hline & Min & -5.0 & -4.9 \\
\hline \multirow[t]{3}{*}{ Asset index } & Max & 5 & 5 \\
\hline & Mean & 3 & 3.1 \\
\hline & Min & 1 & 1 \\
\hline \multirow[t]{3}{*}{ Fraction of dependent age individuals in household } & $\operatorname{Max}$ & 0.9 & 1 \\
\hline & Mean & 0.5 & 0.5 \\
\hline & Min & 0.1 & 0.1 \\
\hline \multirow[t]{3}{*}{ Household size } & Max & 28 & 14 \\
\hline & Mean & 7.6 & 5.2 \\
\hline & Min & 2 & 2 \\
\hline \multirow[t]{3}{*}{ Household head age (years) } & $\operatorname{Max}$ & 97 & 90 \\
\hline & Mean & 39.2 & 39.2 \\
\hline & Min & 18 & 18 \\
\hline \multirow[t]{5}{*}{ Household head's education (\%) } & High school & & 2.6 \\
\hline & Never & & 41.9 \\
\hline & Primary & & 49.5 \\
\hline & Secondary & & 5.4 \\
\hline & University & & 0.6 \\
\hline \multirow[t]{2}{*}{ Household head sex (\%) } & Female & 12.2 & 15.9 \\
\hline & Male & 87.8 & 84.1 \\
\hline \multirow[t]{2}{*}{ Household head literacy (\%) } & Illiterate & 79.6 & 18 \\
\hline & Literate & 20.4 & 82 \\
\hline Household head religion (\%) & Christian & 37.1 & 0.3 \\
\hline
\end{tabular}


Table 4 (continued)

\begin{tabular}{|c|c|c|c|}
\hline & & Ghana & Bangladesh \\
\hline & Hindu & & 9.5 \\
\hline & Muslim & 40.4 & 90.2 \\
\hline & None & 1.6 & \\
\hline & Traditional & 20.9 & \\
\hline \multirow[t]{3}{*}{ Percent of rice area irrigated } & $\operatorname{Max}$ & & 1 \\
\hline & Mean & & 0.5 \\
\hline & Min & & 0 \\
\hline \multirow[t]{3}{*}{ Population within $7.5 \mathrm{~km}$ of household (1000 people) } & Max & 43 & 529 \\
\hline & Mean & 10.2 & 185 \\
\hline & Min & 1.3 & 11.9 \\
\hline \multirow[t]{3}{*}{ Year $(\%)$} & 2011 & & 52.7 \\
\hline & 2012 & 100 & \\
\hline & 2015 & & 47.3 \\
\hline \multirow[t]{3}{*}{ 12-month standardized precipitation index } & $\operatorname{Max}$ & 1.5 & 2.6 \\
\hline & Mean & 0.8 & -0.2 \\
\hline & Min & -0.5 & -1.7 \\
\hline \multirow[t]{3}{*}{ 24-month standardized precipitation index } & Max & 1.7 & 2.2 \\
\hline & Mean & 1.1 & -0.5 \\
\hline & Min & 0.3 & -2.3 \\
\hline \multirow[t]{3}{*}{ 36-month standardized precipitation index } & $\operatorname{Max}$ & 2.3 & 2.3 \\
\hline & Mean & 1.4 & -0.6 \\
\hline & Min & 0.4 & -2.3 \\
\hline \multirow[t]{3}{*}{ 48-month standardized precipitation index } & $\operatorname{Max}$ & 2.2 & 2.3 \\
\hline & Mean & 1.4 & -0.7 \\
\hline & Min & 0.3 & -2.2 \\
\hline \multirow[t]{3}{*}{ 60-month standardized precipitation index } & Max & 2.5 & 3.1 \\
\hline & Mean & 1.6 & -0.4 \\
\hline & Min & 0.4 & -2.5 \\
\hline \multirow[t]{3}{*}{ Average annual precipitation (1000 mm) } & Max & 1.4 & 5 \\
\hline & Mean & 1.1 & 2.5 \\
\hline & Min & 0.9 & 1.4 \\
\hline
\end{tabular}


Table 5 Household hunger

\begin{tabular}{|c|c|c|c|}
\hline & & Ghana & Bangladesh \\
\hline \multirow[t]{3}{*}{ Asset index } & Max & 5 & 5 \\
\hline & Mean & 3 & 3 \\
\hline & Min & 1 & 1 \\
\hline \multirow[t]{3}{*}{ Fraction of dependent age individuals in household } & Max & 1 & 1 \\
\hline & Mean & 0.4 & 0.4 \\
\hline & Min & 0 & 0 \\
\hline \multirow[t]{3}{*}{ Household size } & $\operatorname{Max}$ & 28 & 14 \\
\hline & Mean & 5.8 & 4.4 \\
\hline & Min & 1 & 1 \\
\hline \multirow[t]{3}{*}{ Household head age (years) } & $\operatorname{Max}$ & 100 & 105 \\
\hline & Mean & 45.1 & 45.2 \\
\hline & Min & 15 & 17 \\
\hline \multirow[t]{2}{*}{ Household head gender (\%) } & Female & 18.2 & 18.6 \\
\hline & Male & 81.8 & 81.4 \\
\hline \multirow[t]{2}{*}{ Household head literacy (\%) } & Literate & 21 & 78.3 \\
\hline & Illiterate & 79 & 21.7 \\
\hline \multirow[t]{5}{*}{ Household head education (\%) } & Primary & & 44.9 \\
\hline & Education & & 5.8 \\
\hline & High school & & 2.3 \\
\hline & University & & 0.6 \\
\hline & None & & 46.3 \\
\hline \multirow[t]{5}{*}{ Household head religion $(\%)$} & Christian & 40.9 & 0.3 \\
\hline & Hindu & & 11.2 \\
\hline & Muslim & 35.1 & 88.6 \\
\hline & None & 2.1 & \\
\hline & Traditional & 21.9 & \\
\hline \multirow[t]{7}{*}{ Household Hunger Scale (HHS) score } & 0 & $1022(43.2 \%)$ & $8328(89.1 \%)$ \\
\hline & 1 & $261(11.0 \%)$ & $548(5.9 \%)$ \\
\hline & 2 & $507(21.5 \%)$ & $269(2.9 \%)$ \\
\hline & 3 & $549(23.2 \%)$ & $140(1.5 \%)$ \\
\hline & 4 & $15(0.6 \%)$ & $32(3.4 \%)$ \\
\hline & 5 & $5(0.2 \%)$ & $10(0.1 \%)$ \\
\hline & 6 & $3(0.2 \%)$ & $15(0.2 \%)$ \\
\hline \multirow[t]{3}{*}{ Percent of rice area irrigated } & Max & & 1 \\
\hline & Mean & & 0.5 \\
\hline & Min & & 0 \\
\hline \multirow[t]{3}{*}{ Population within $7.5 \mathrm{~km}$ of household } & $\operatorname{Max}$ & 43,000 & 577,000 \\
\hline & Mean & 10,700 & 185,000 \\
\hline & Min & 1340 & 11,900 \\
\hline \multirow[t]{3}{*}{ Year $(\%)$} & 2011 & & 51.4 \\
\hline & 2012 & 100 & \\
\hline & 2015 & & 48.6 \\
\hline
\end{tabular}


Table 5 (continued)

\begin{tabular}{llll}
\hline & & Ghana & Bangladesh \\
\hline 12-month standardized precipitation index & Max & 2.6 & 1.5 \\
& Mean & -0.2 & 0.7 \\
24-month standardized precipitation index & Min & -1.9 & -0.5 \\
& Max & 2.2 & 1.7 \\
36-month standardized precipitation index & Mean & -0.6 & 1 \\
& Min & -2.3 & 0.3 \\
48-month standardized precipitation index & Max & 2.3 & 2.3 \\
& Mean & -0.8 & 1.3 \\
60-month standardized precipitation index & Min & -2.5 & 0.4 \\
& Max & 2.3 & 2.2 \\
& Mean & -0.8 & 1.3 \\
Average annual precipitation (1000 mm) & Min & -2.2 & 0.3 \\
& Max & 3.1 & 2.5 \\
& Mean & -0.6 & 1.5 \\
& Min & -2.7 & 0.4 \\
& Max & 1.4 & 5 \\
\hline & Mean & 1.1 & 2.3 \\
& Min & 0.9 & 1.4 \\
\hline
\end{tabular}




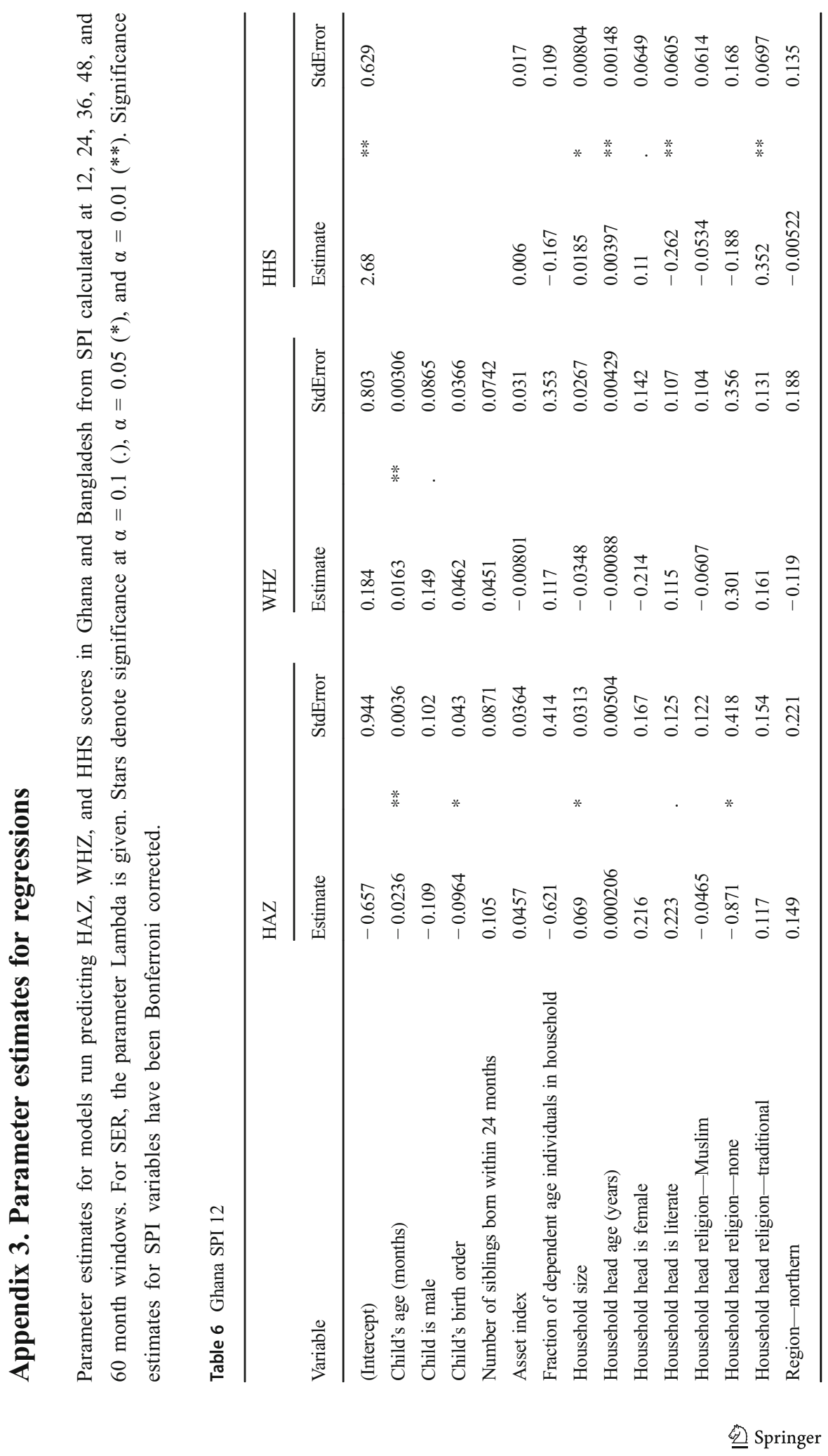




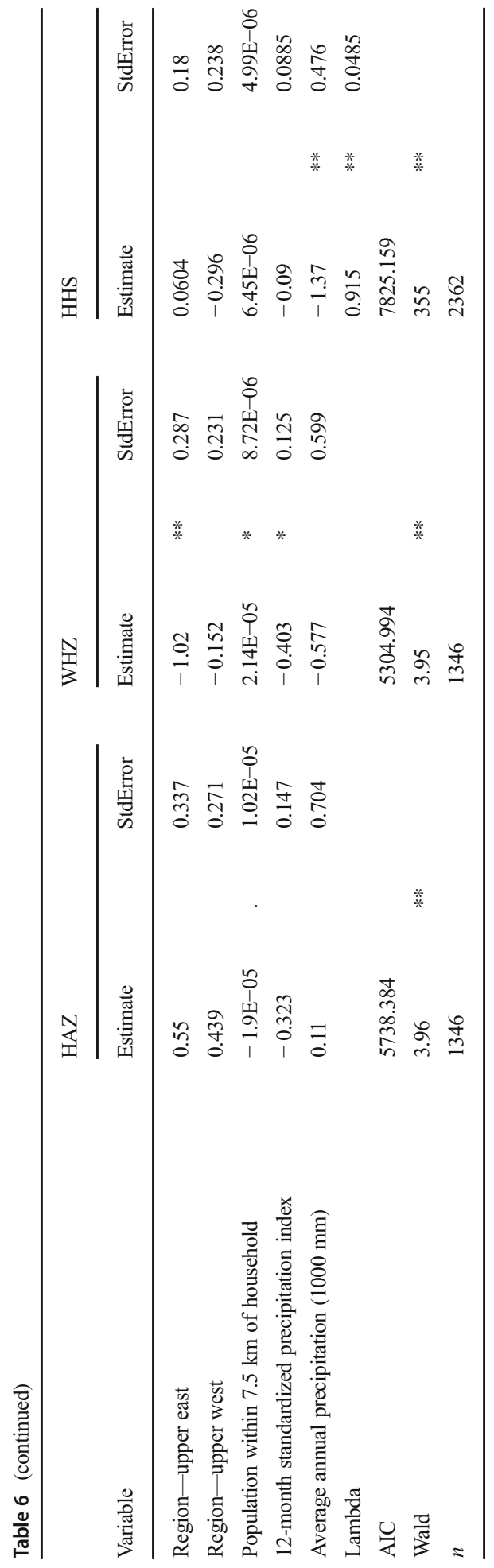




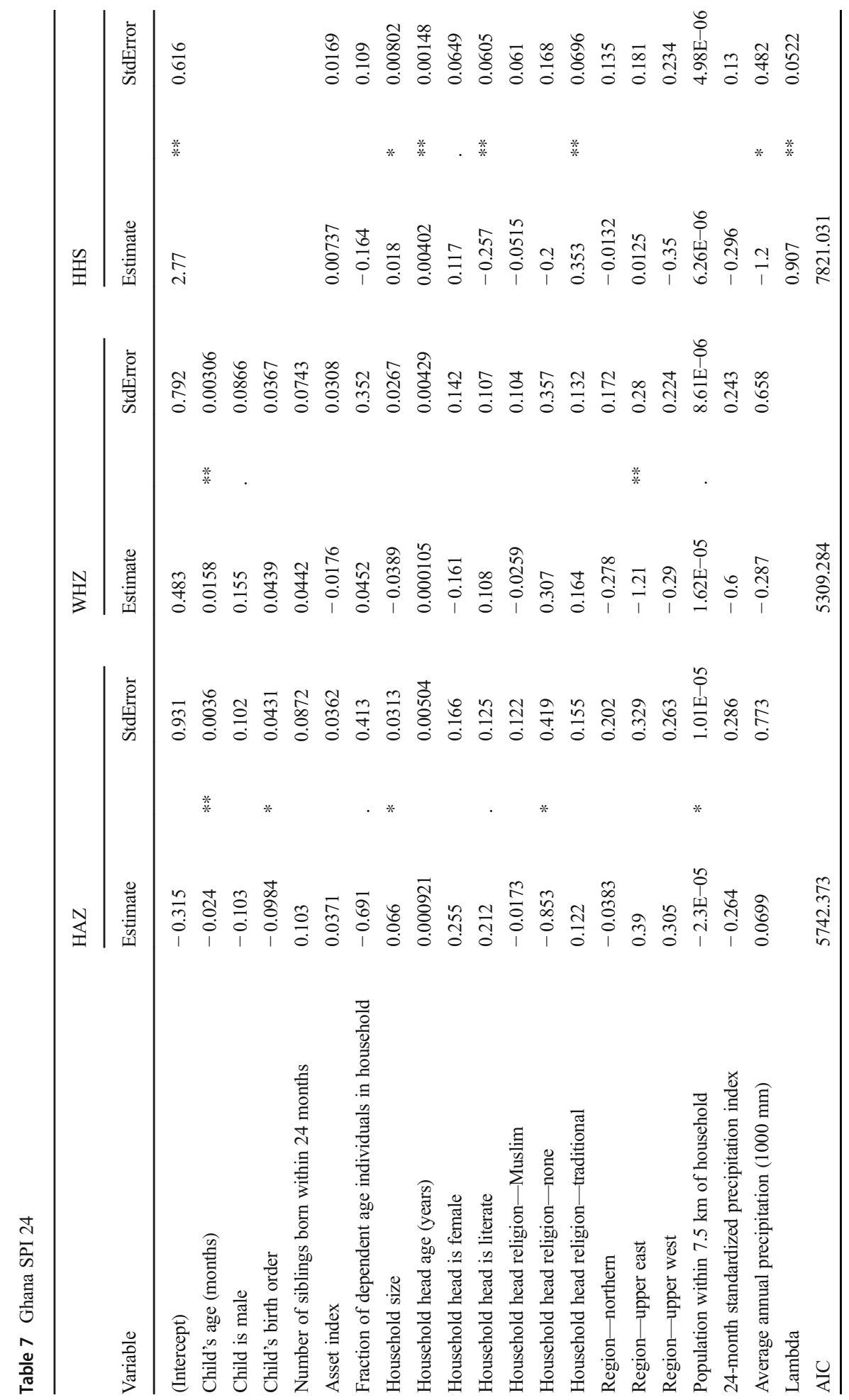




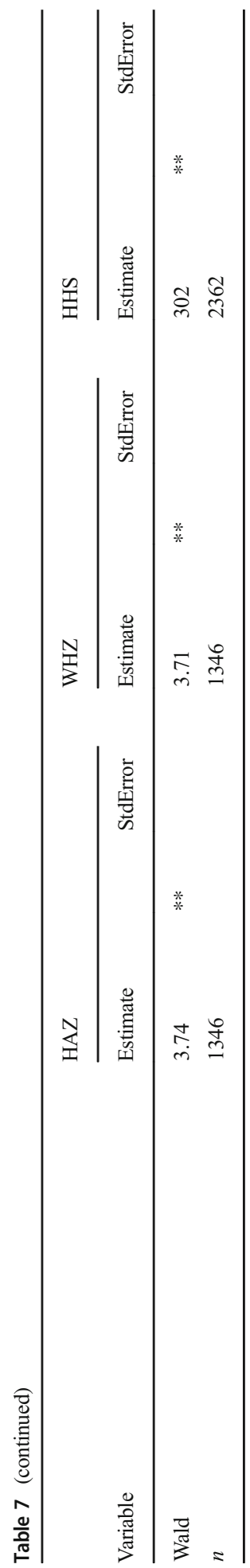

\section{Springer}




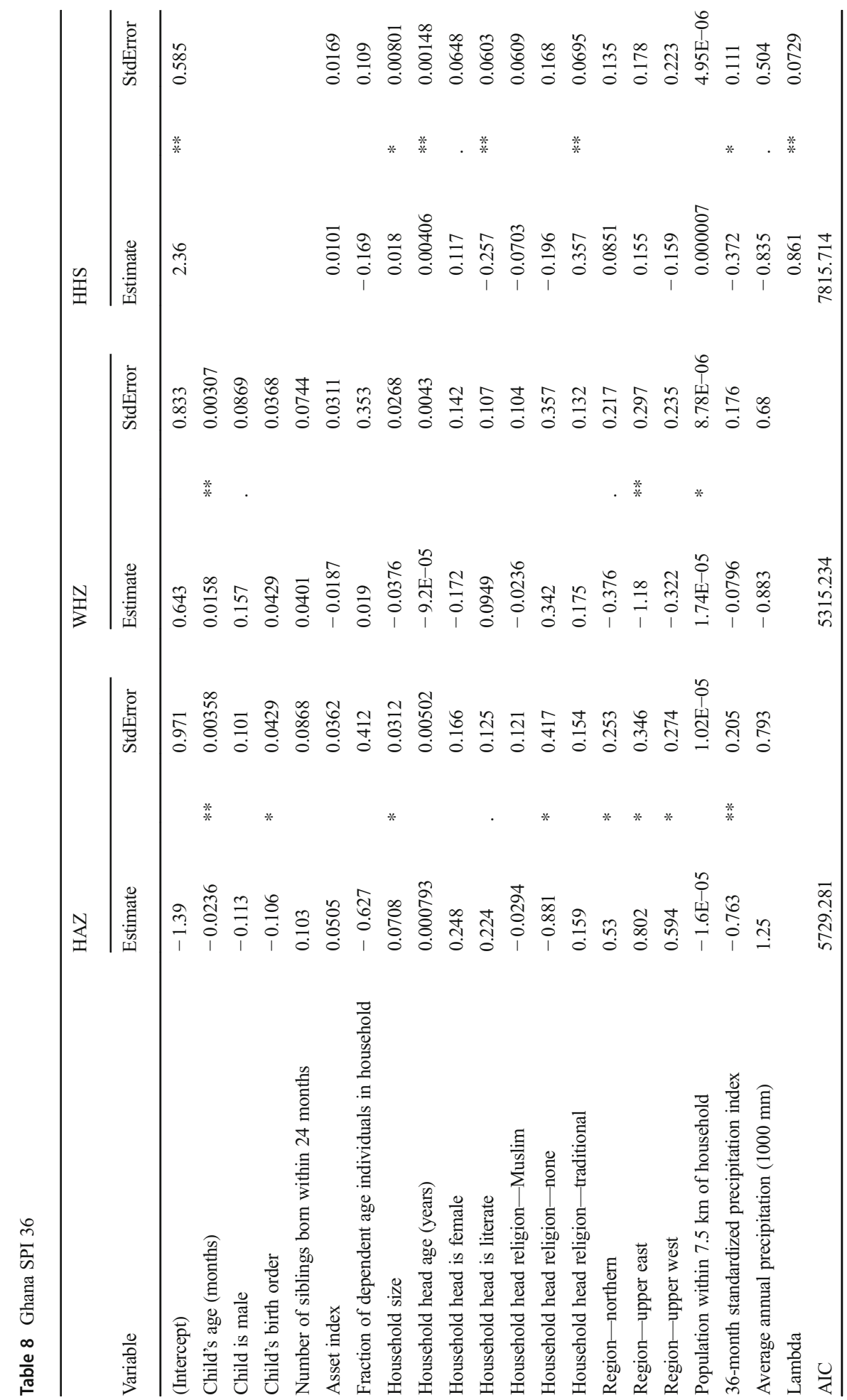




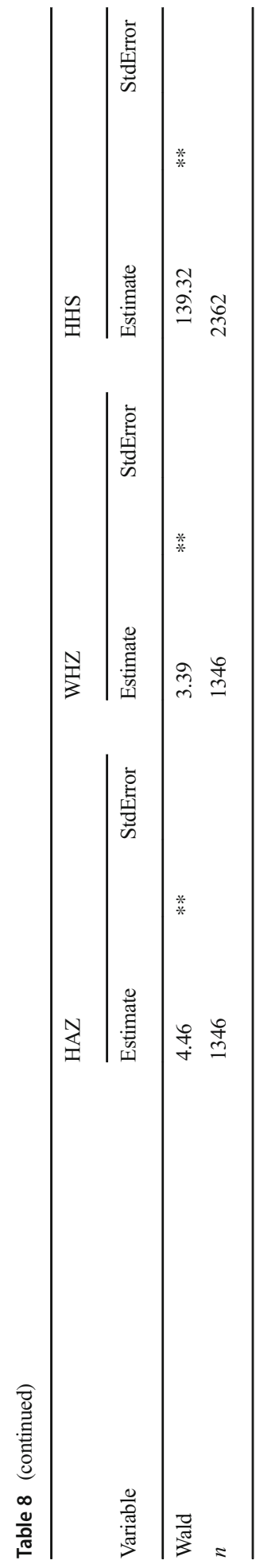

\section{Springer}




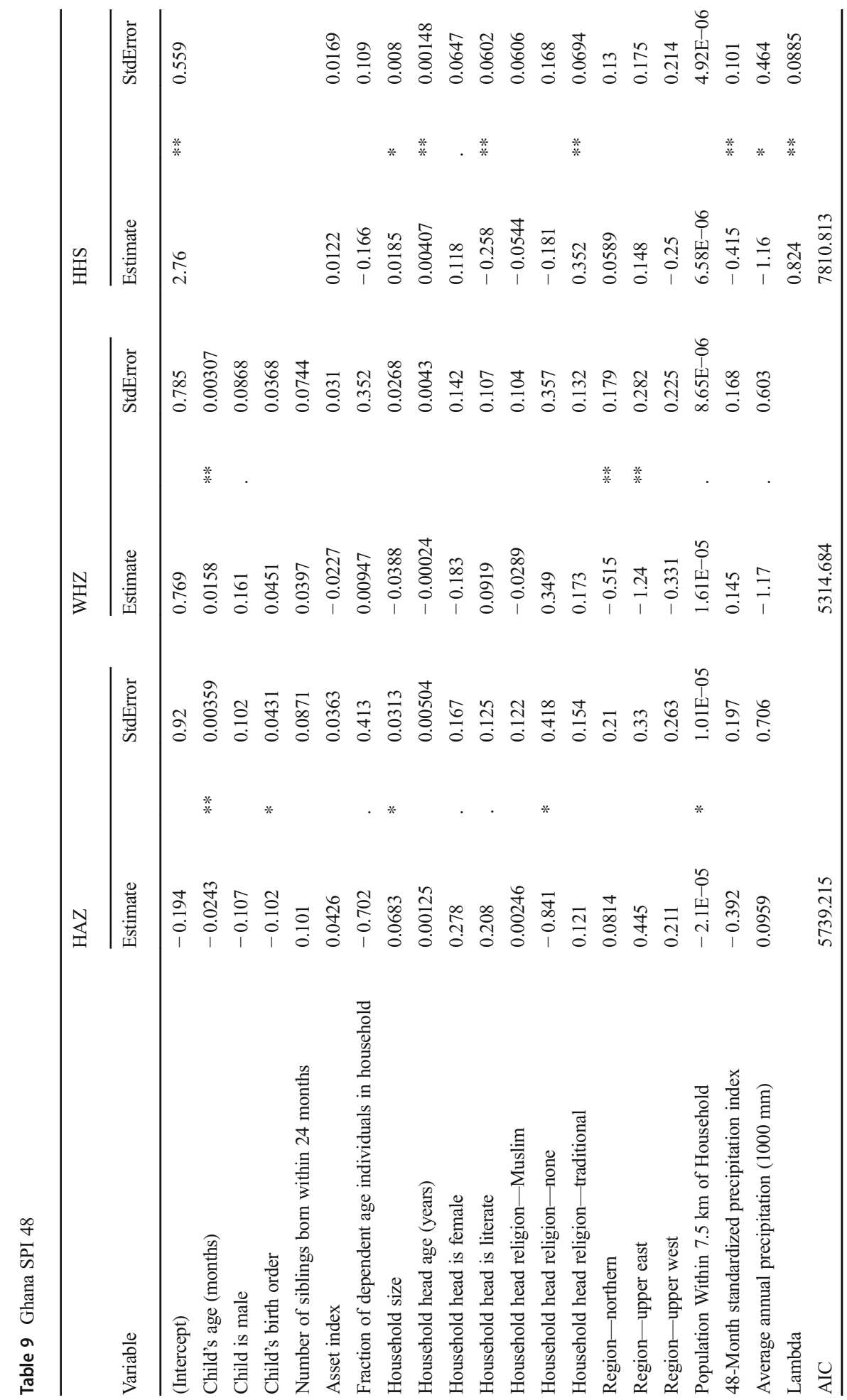




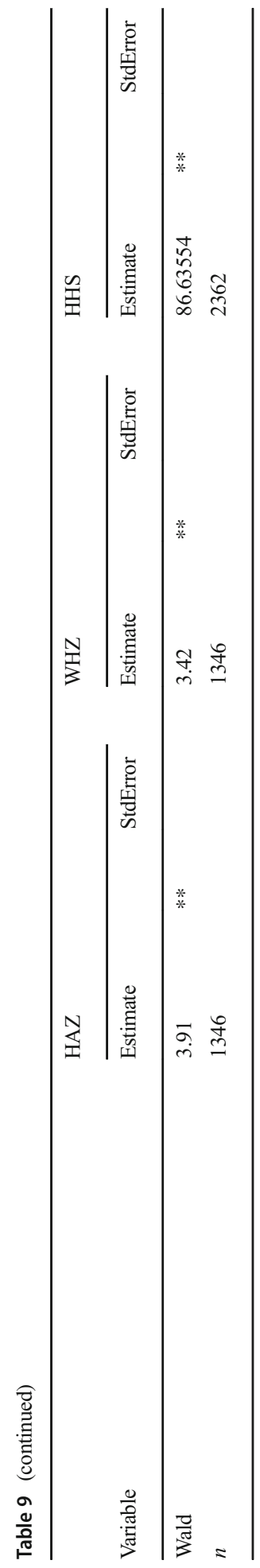

\section{Springer}




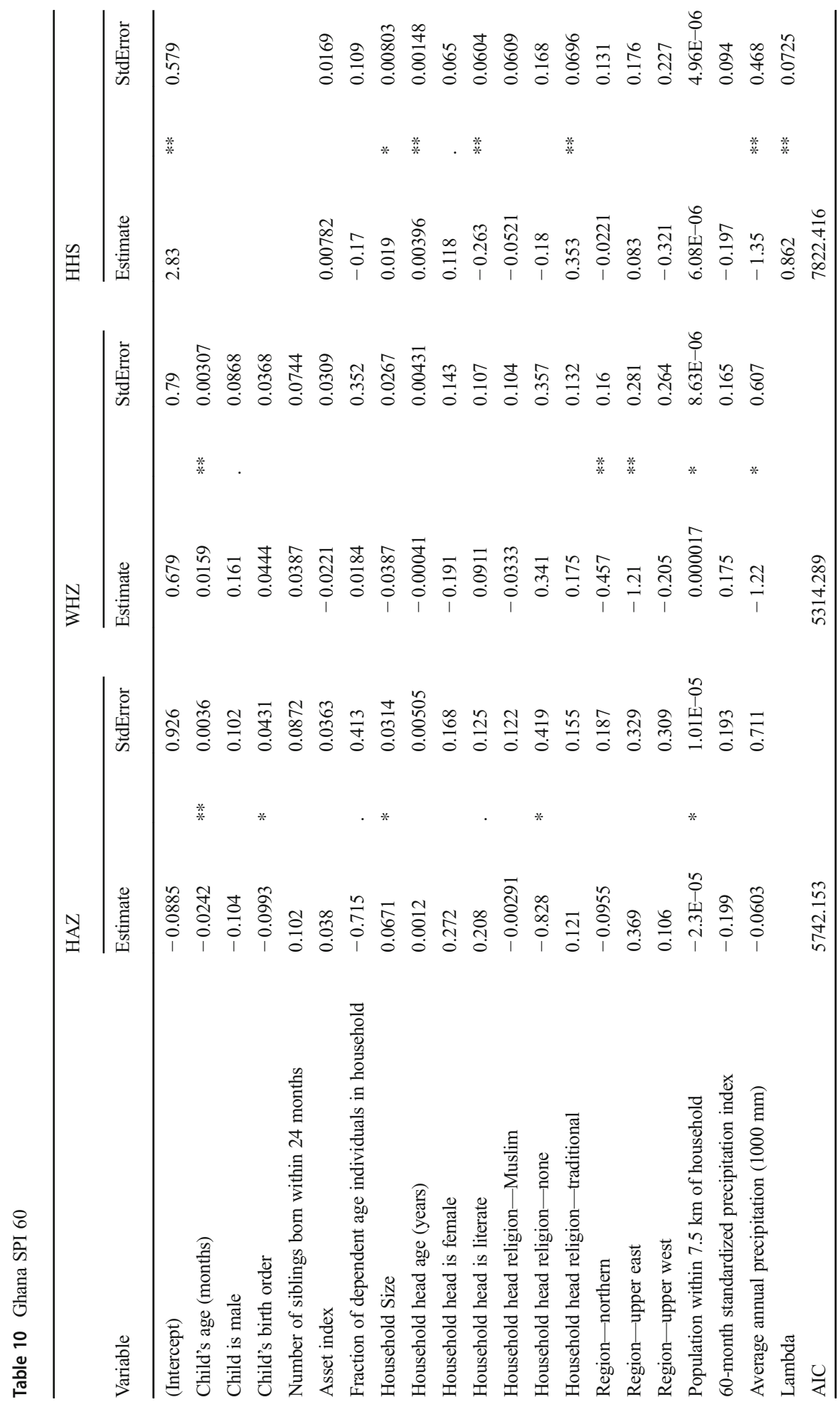




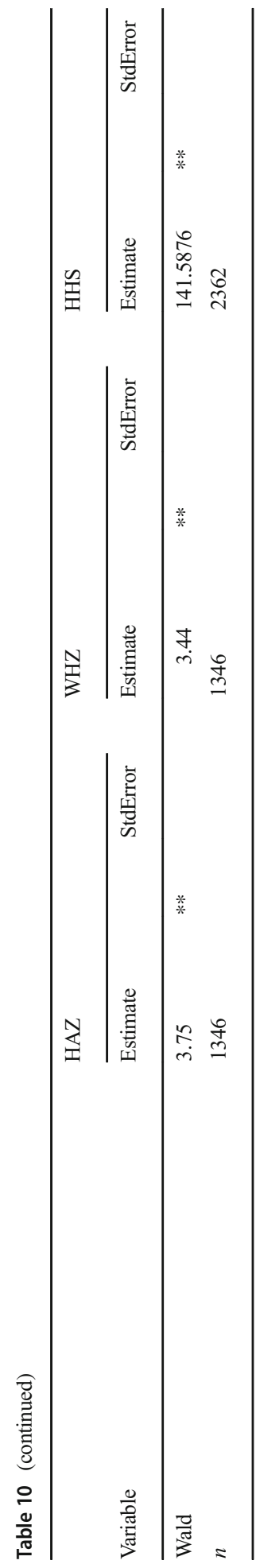

\section{Springer}




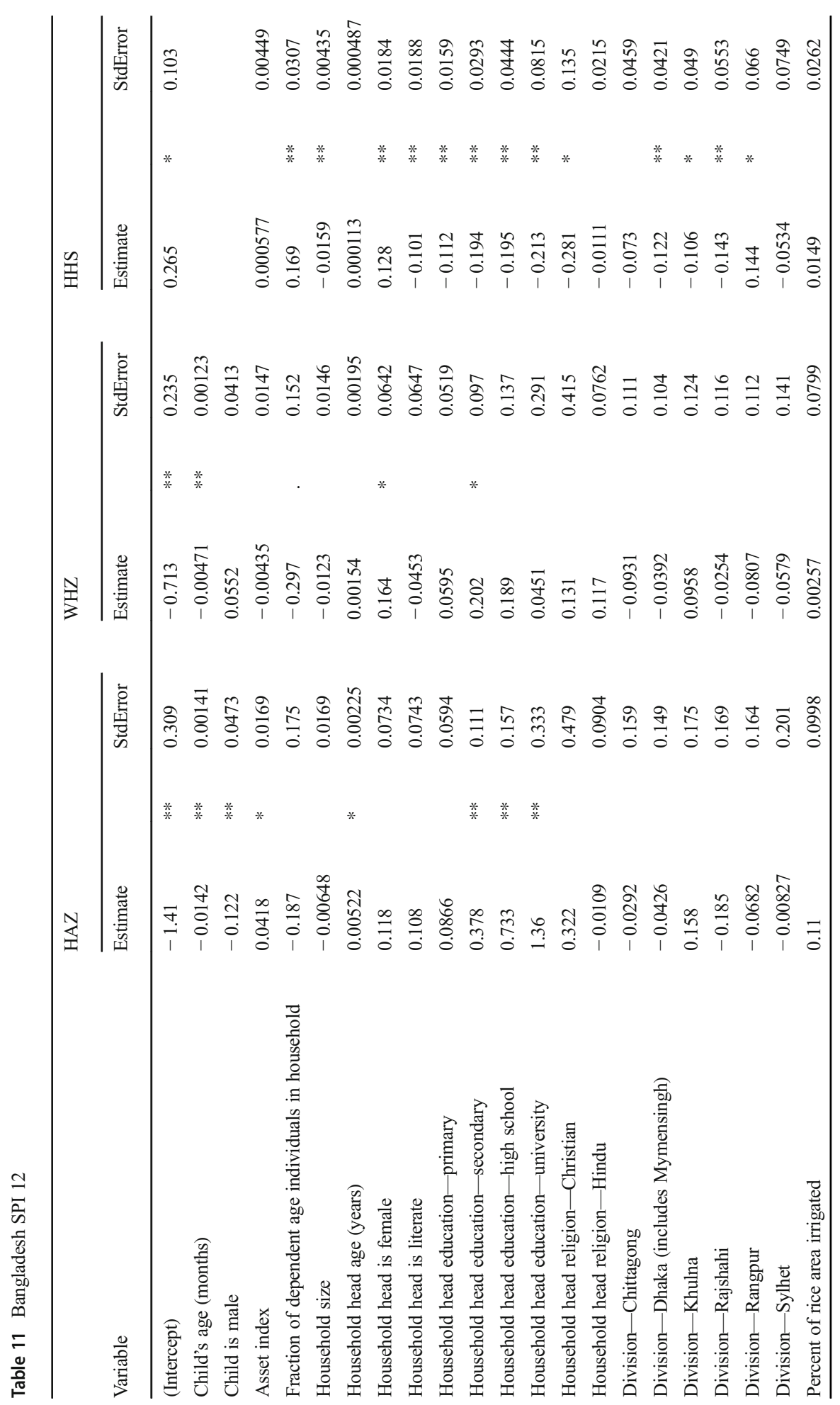




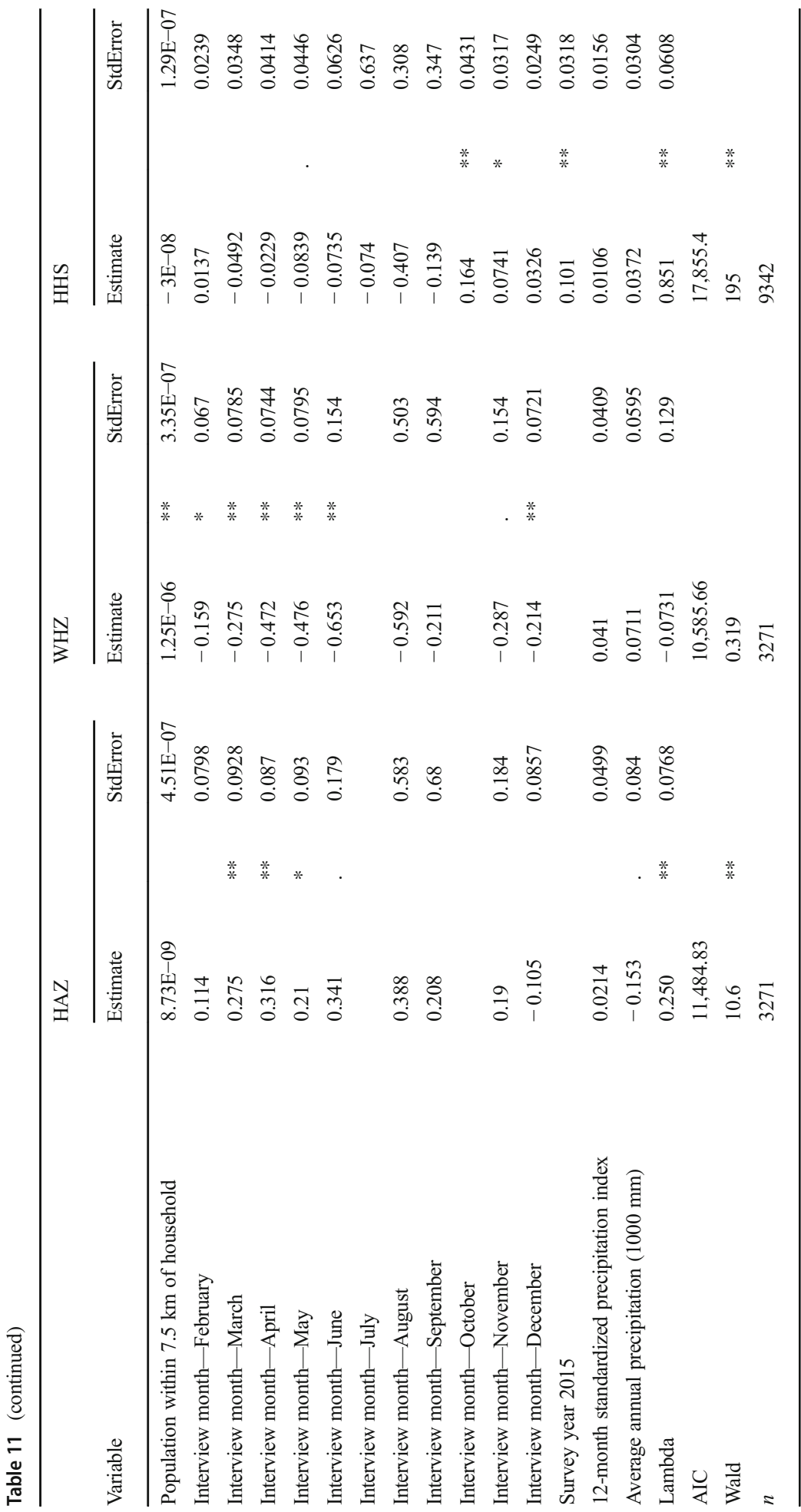




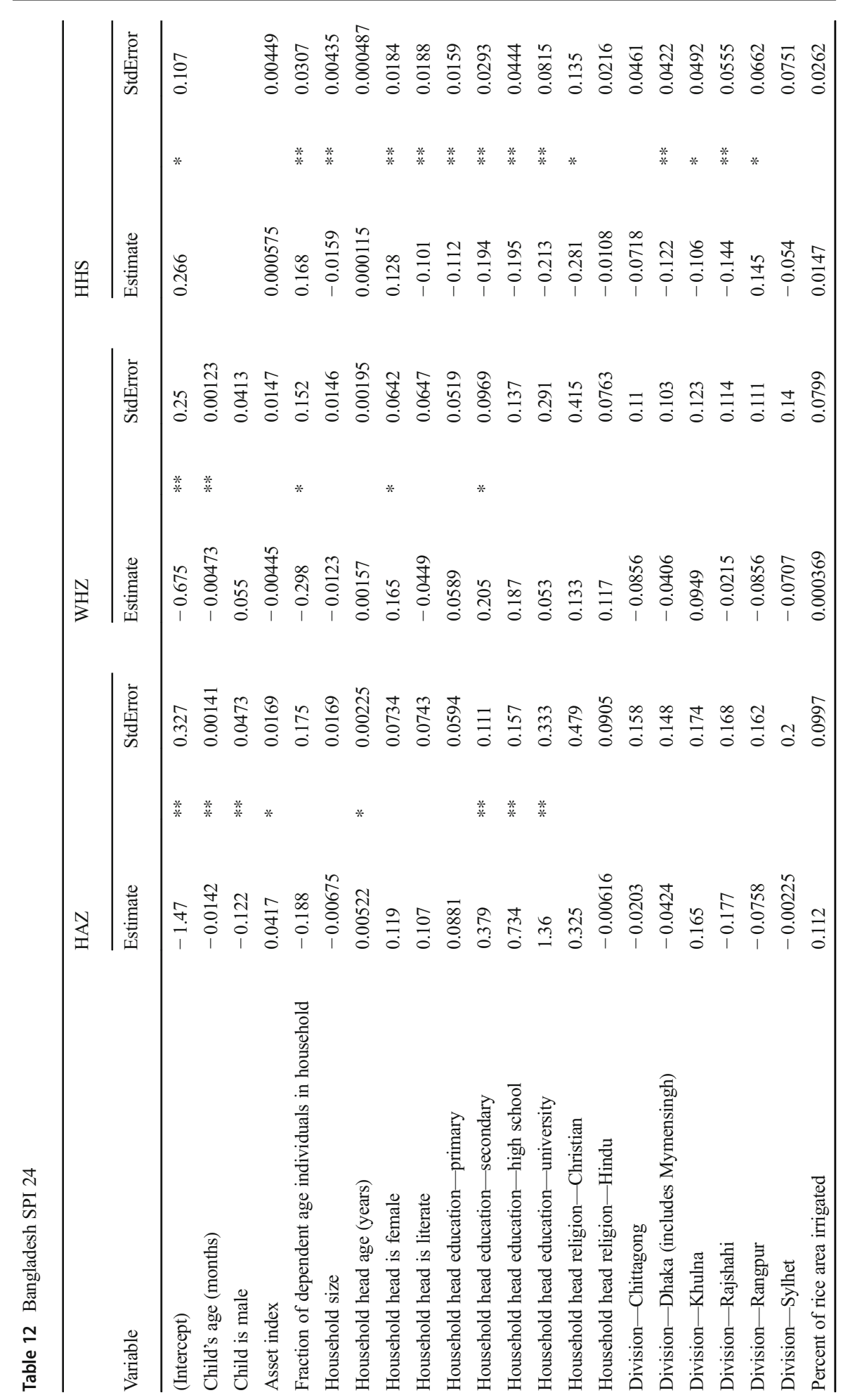




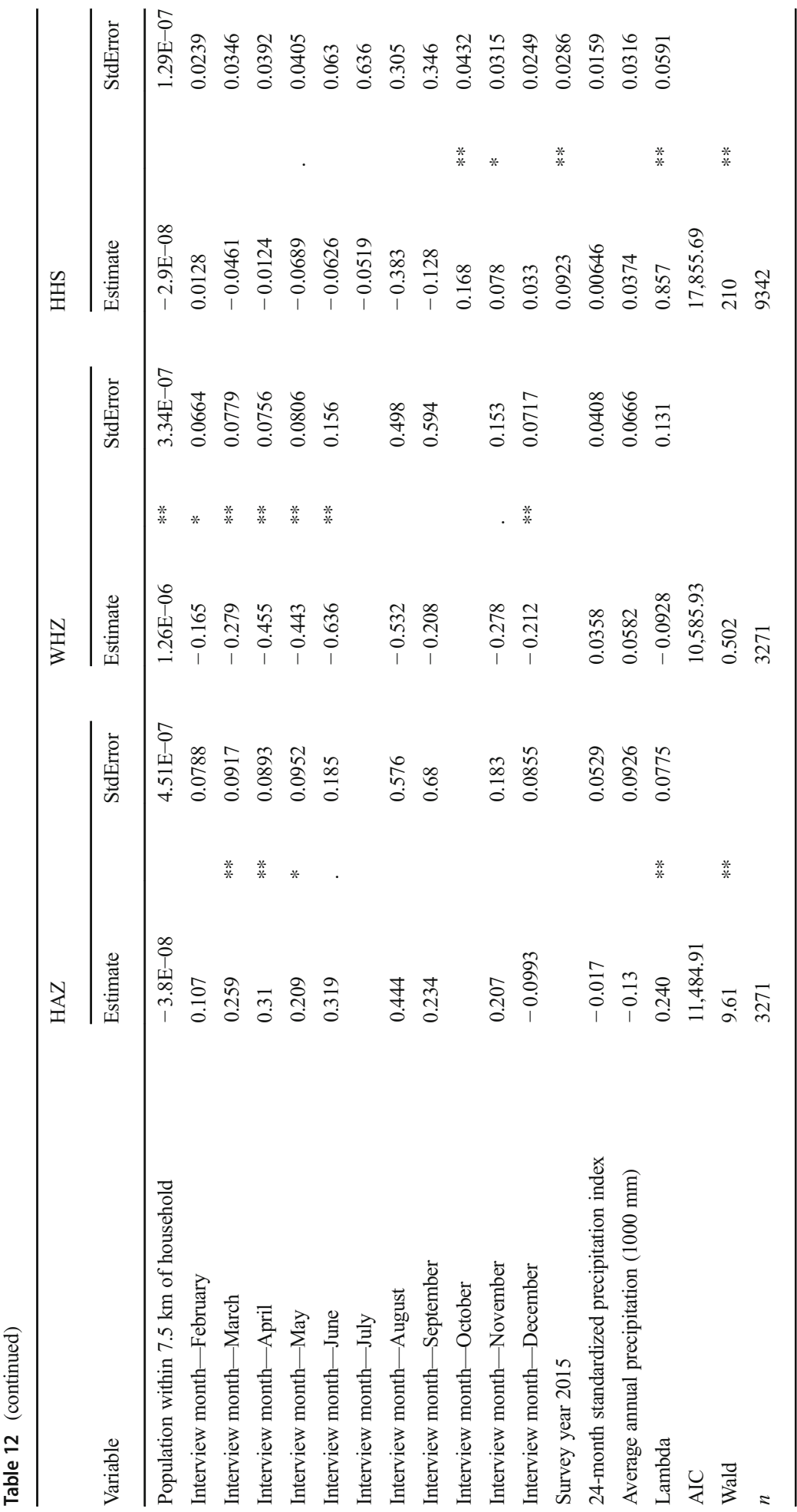




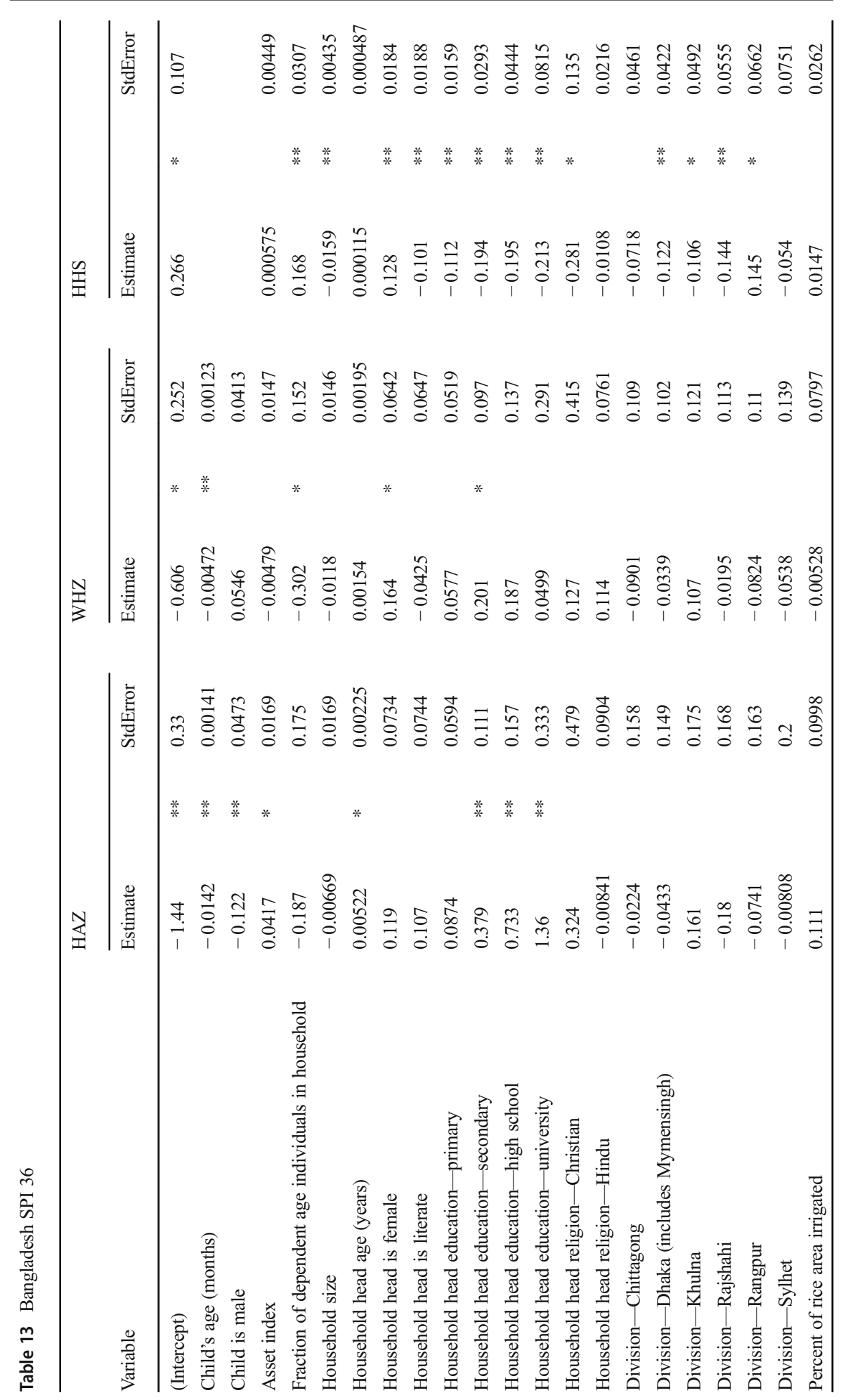




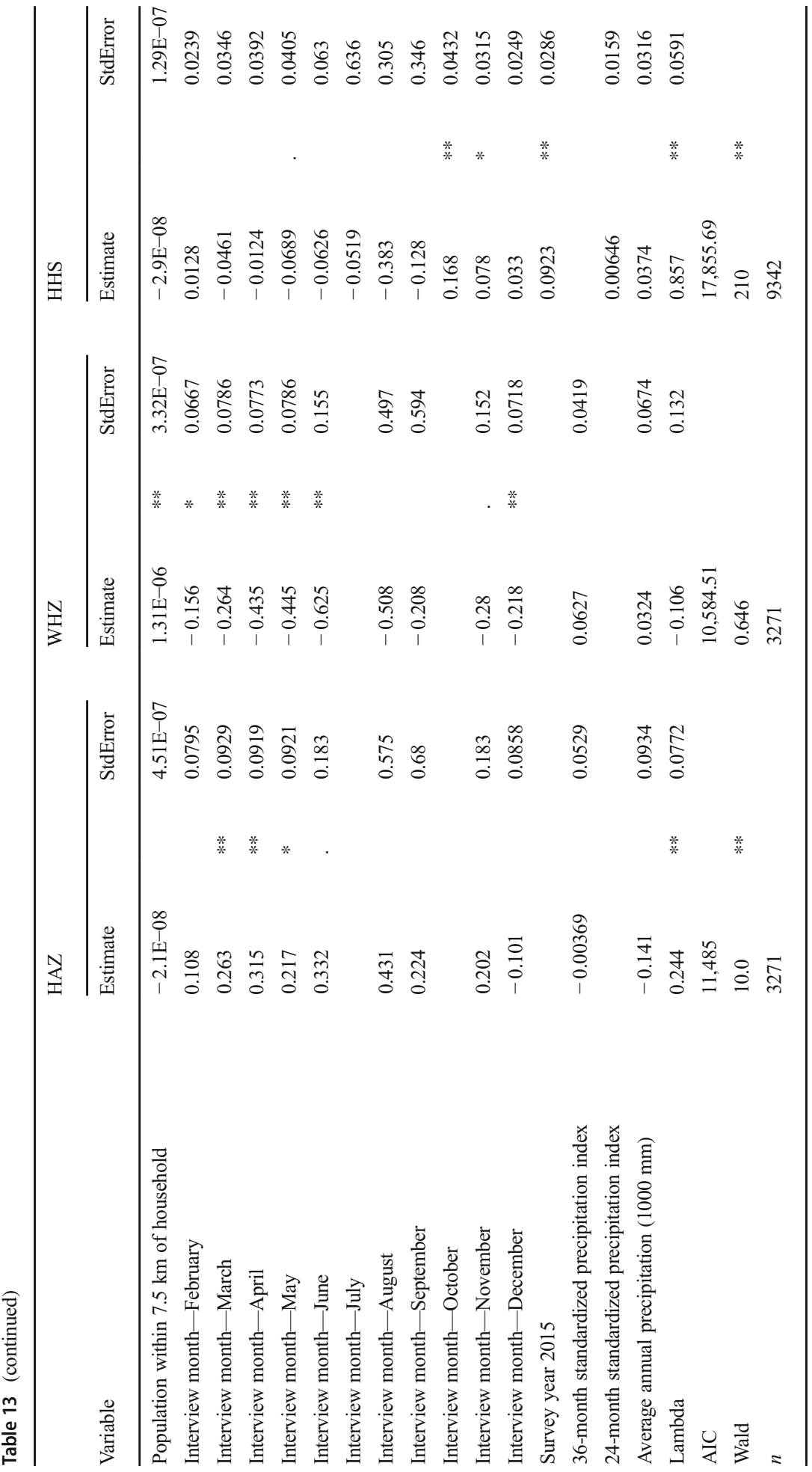




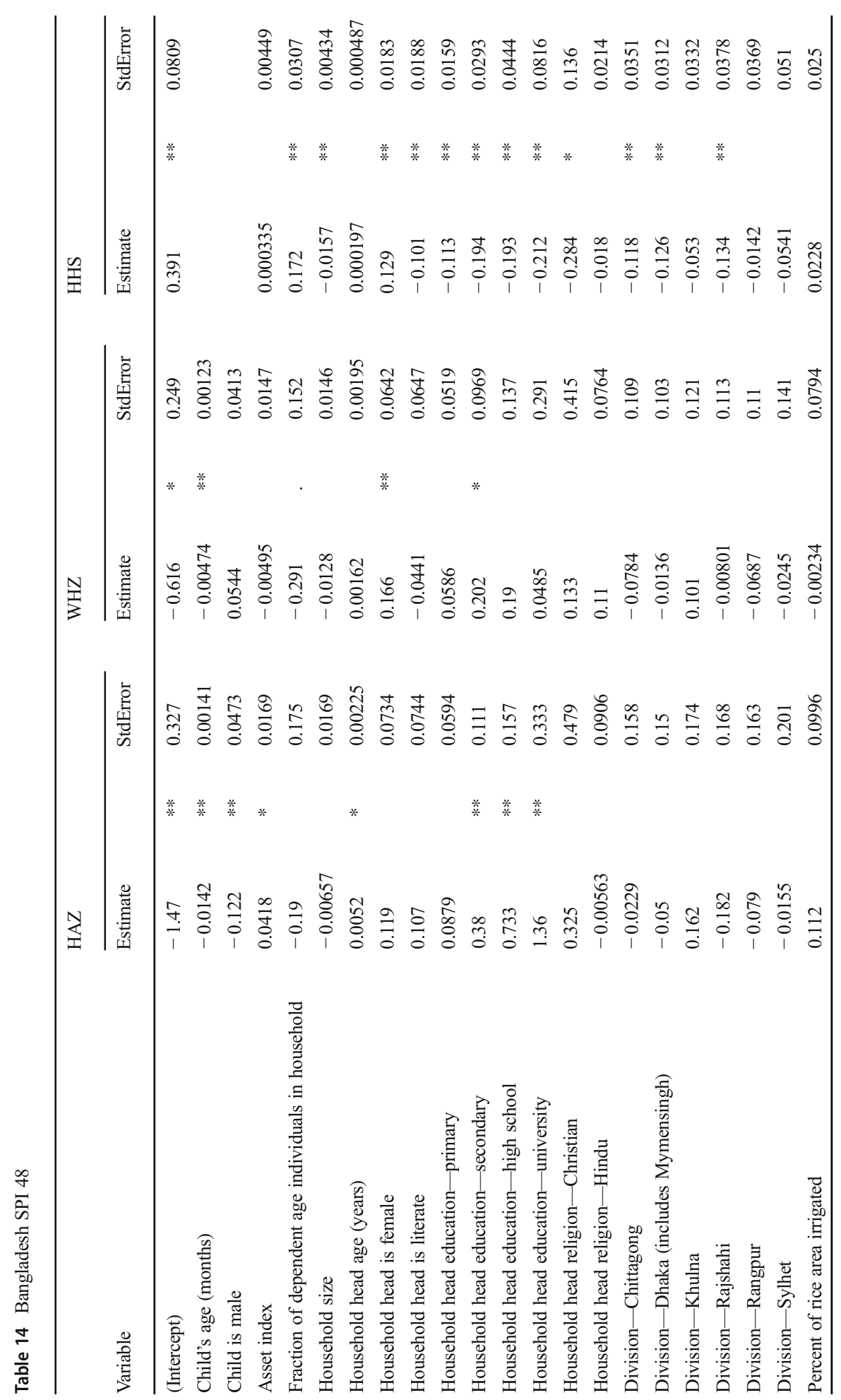




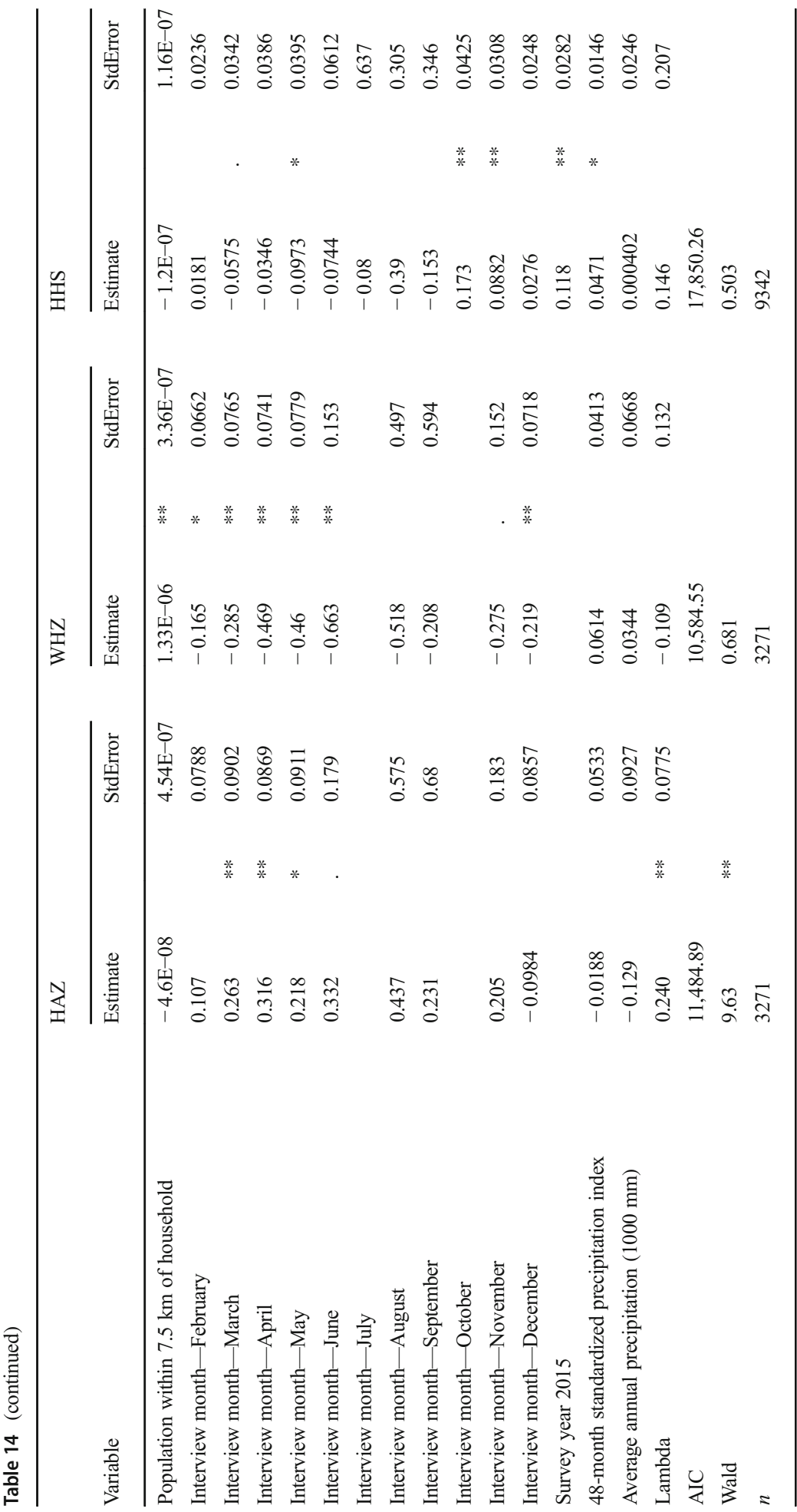




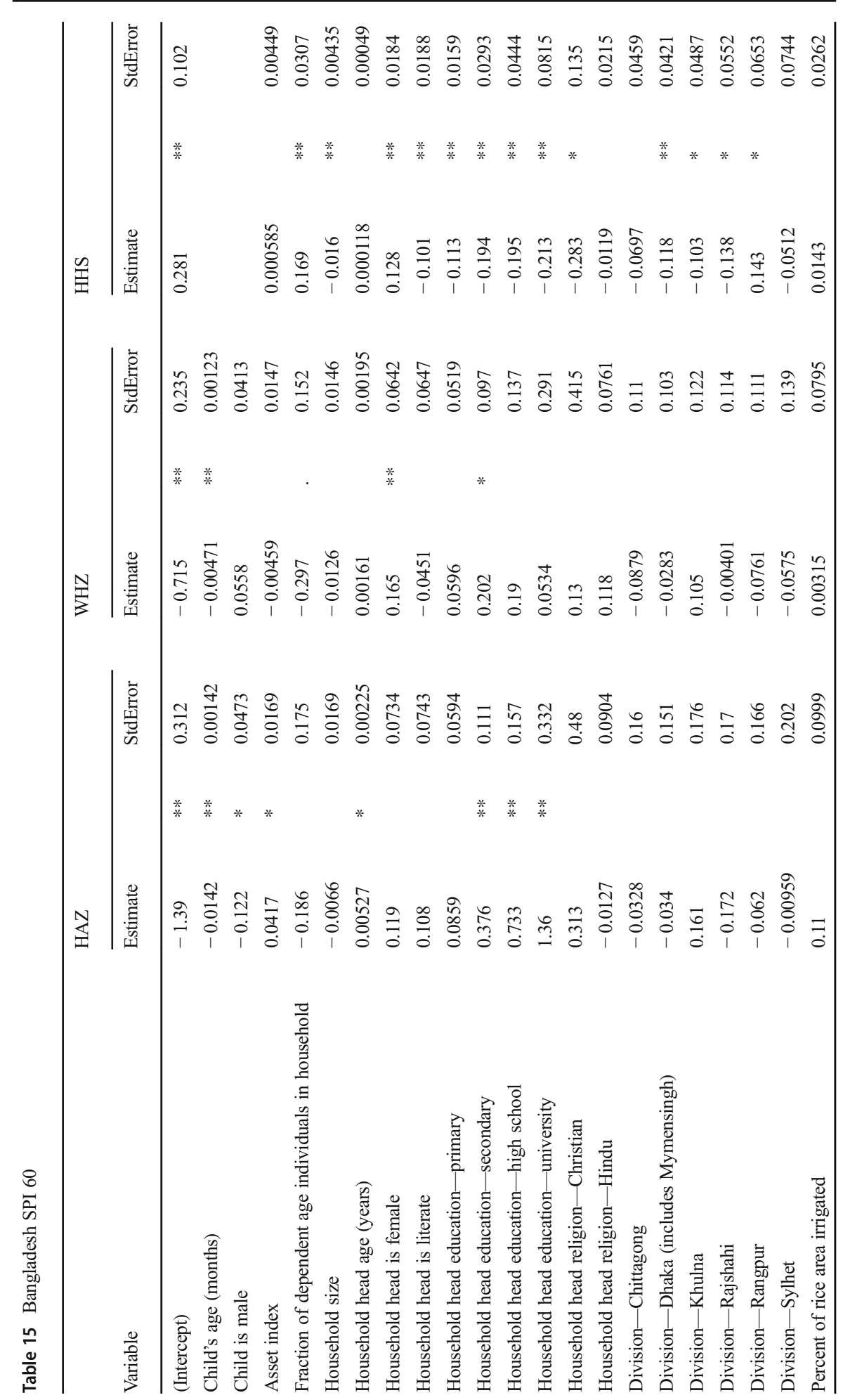




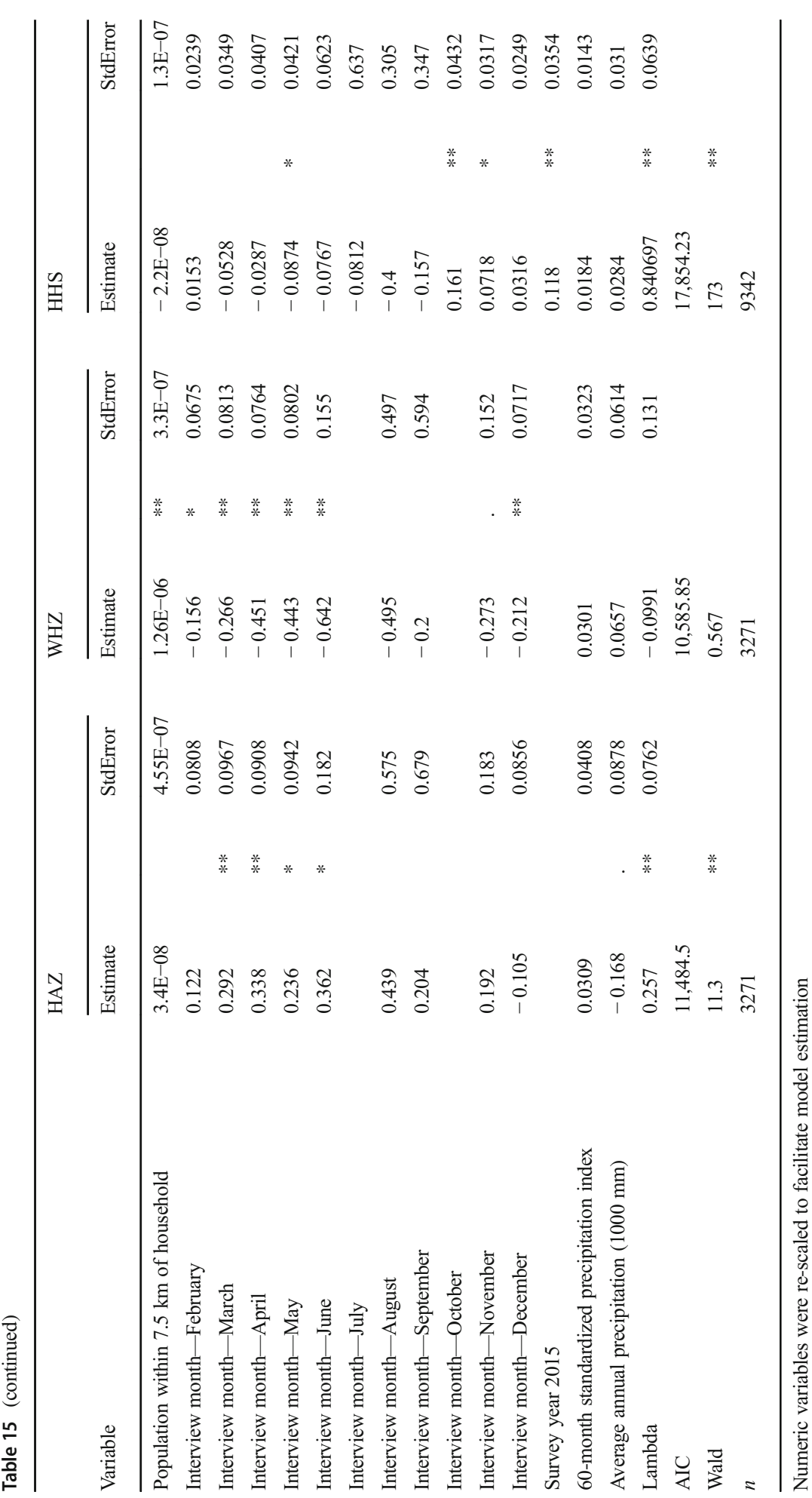




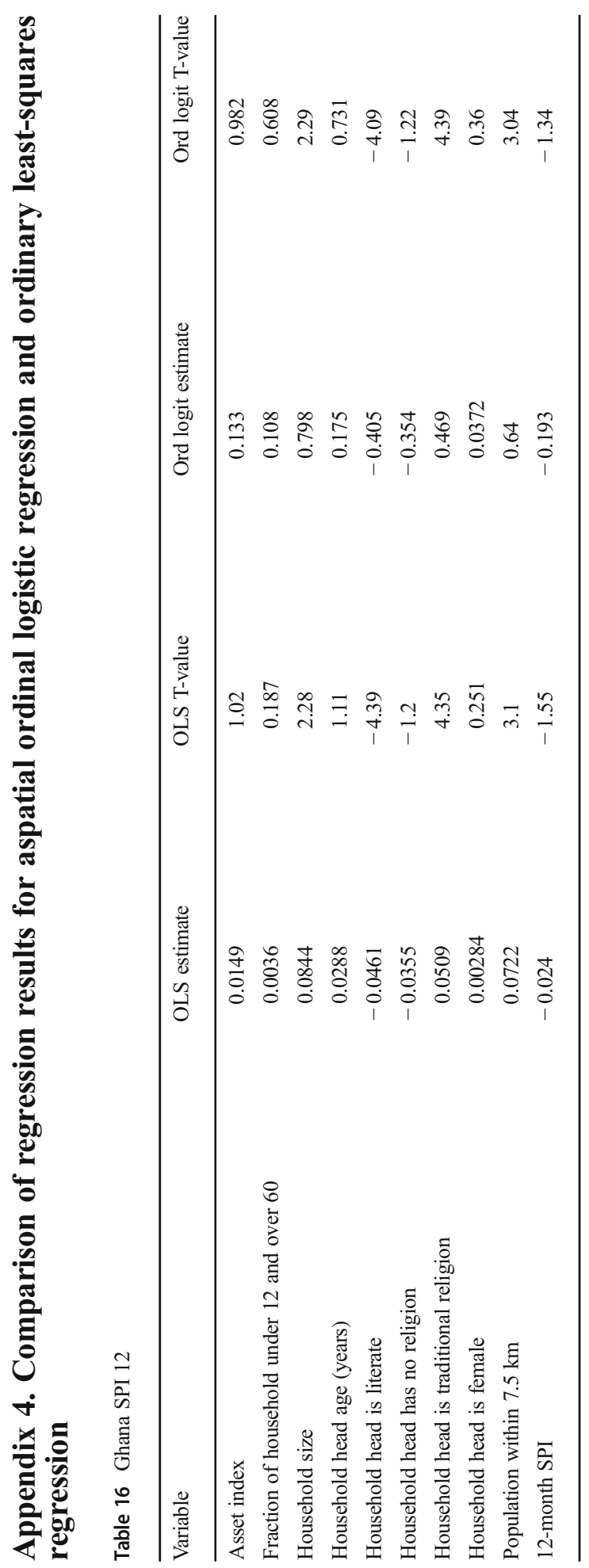




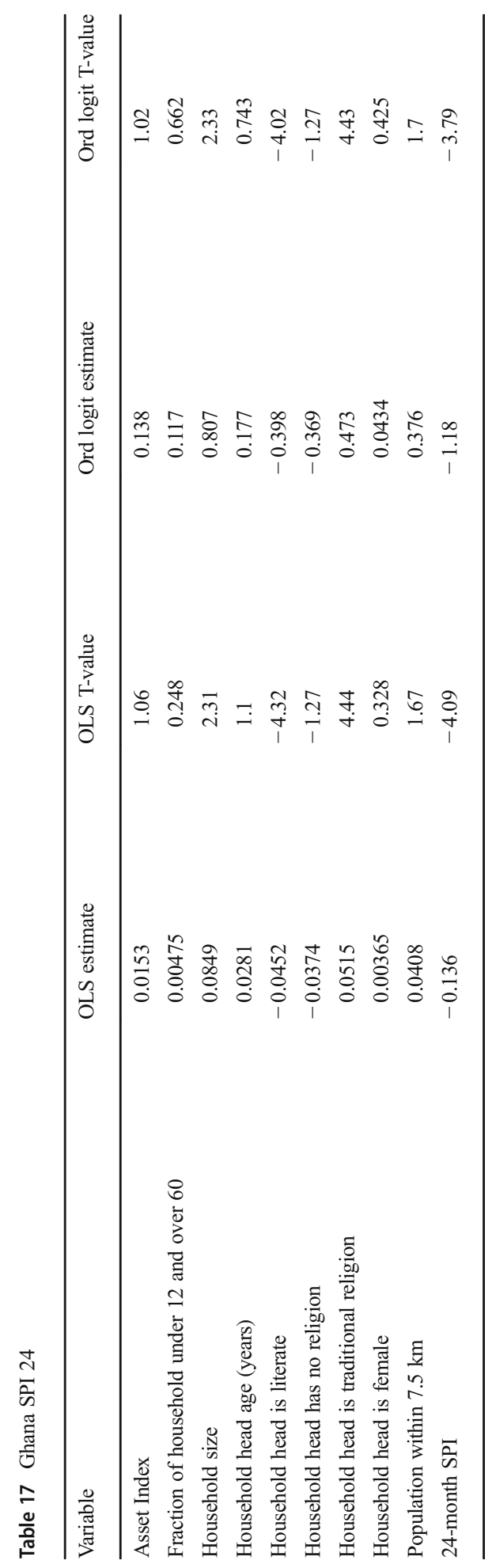




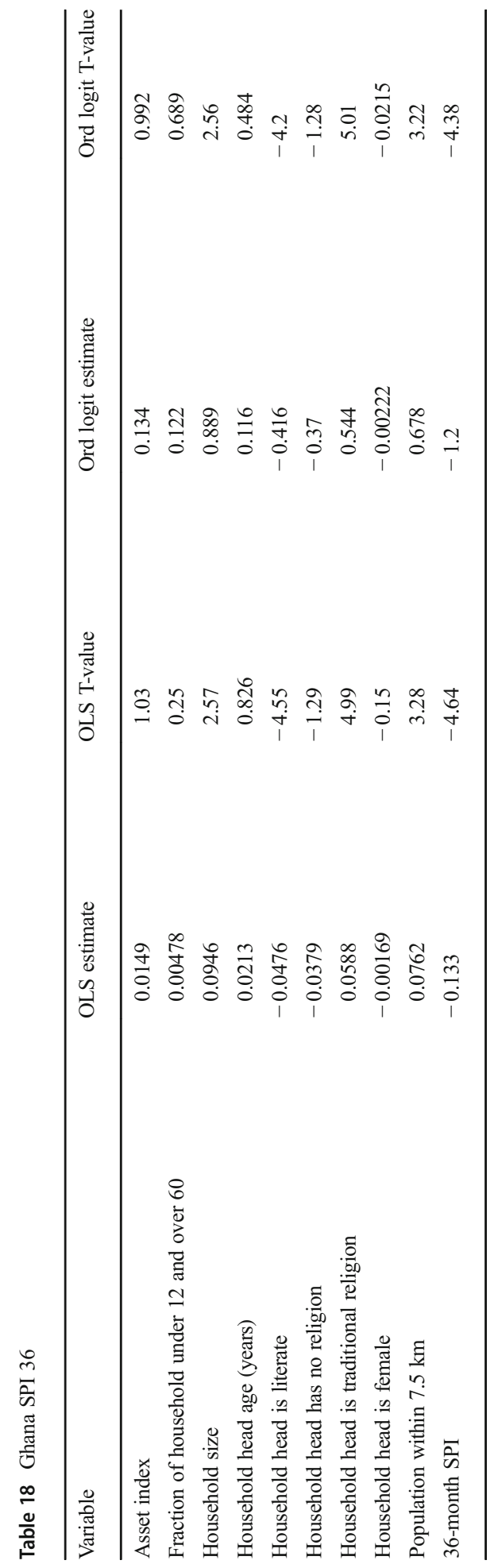




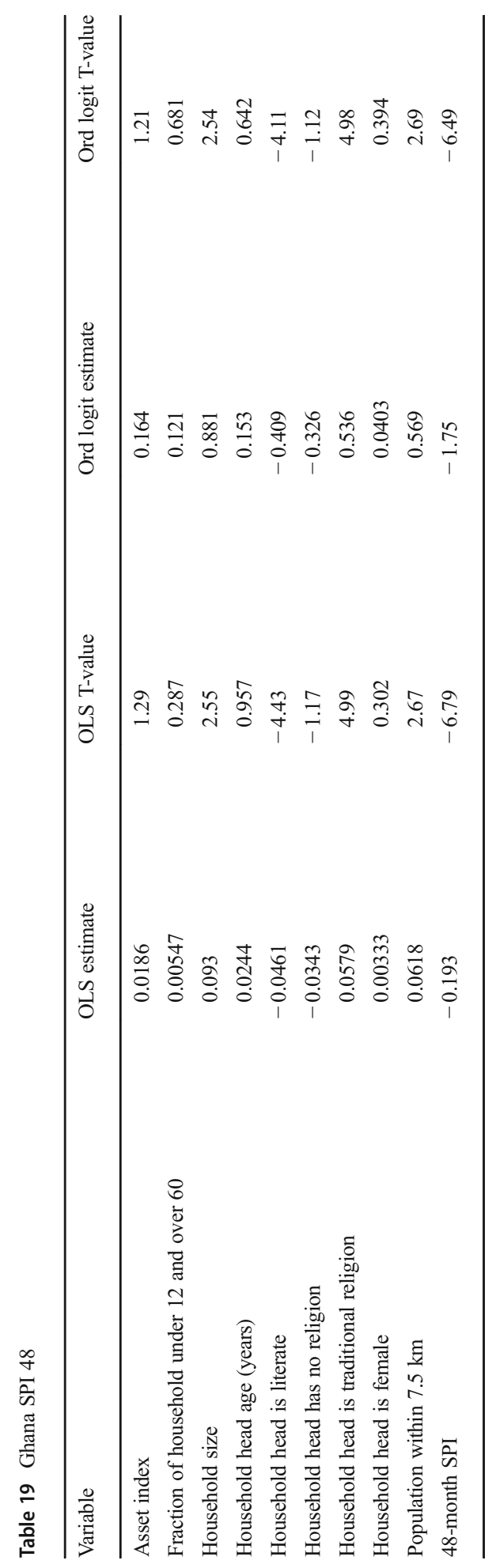




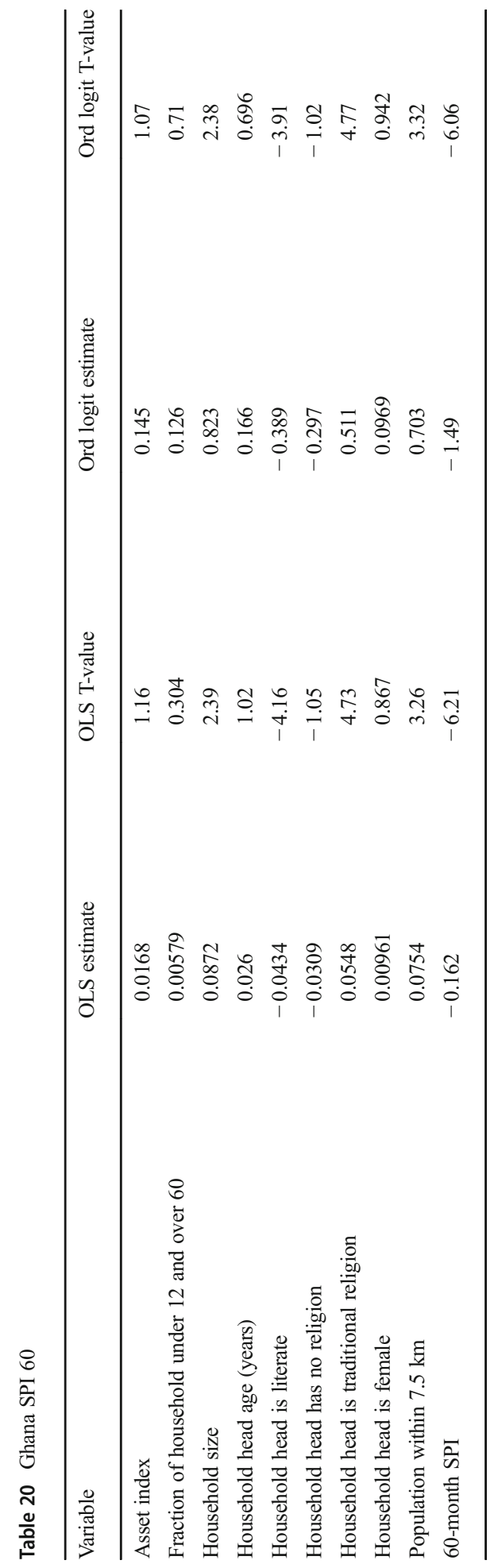




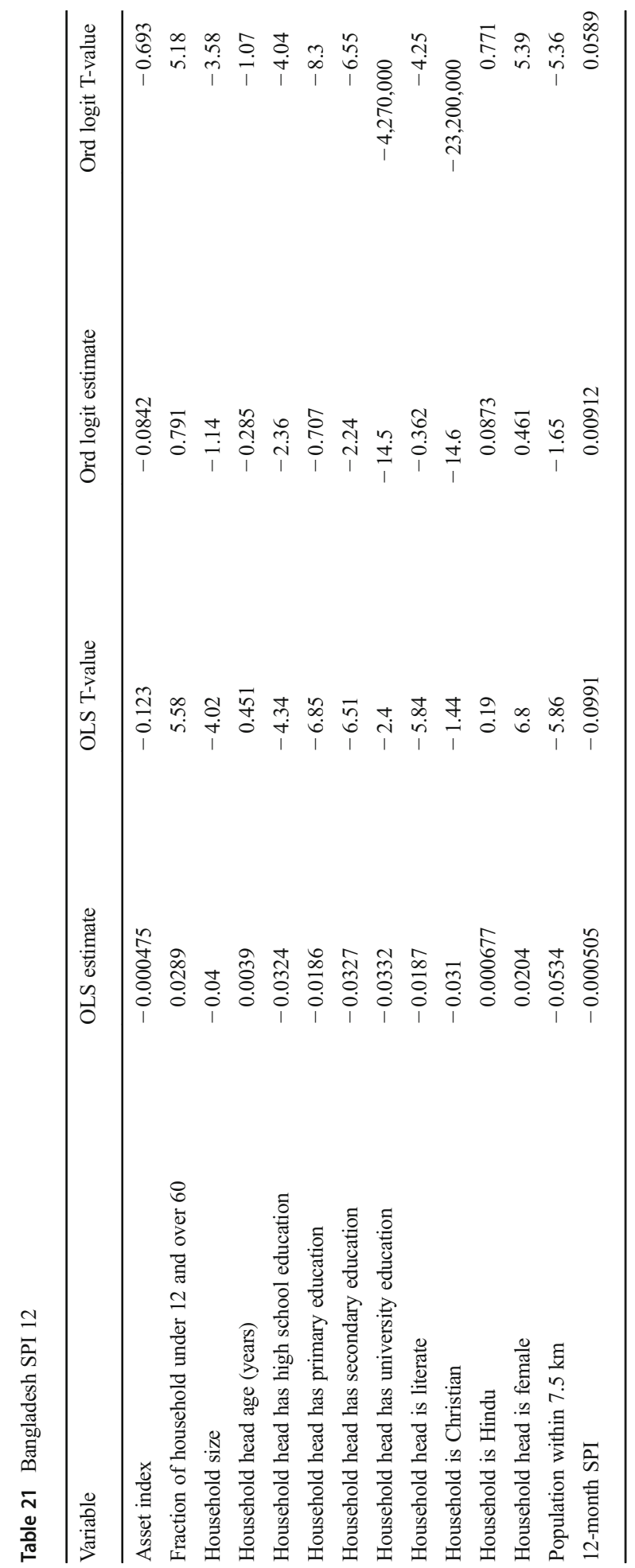




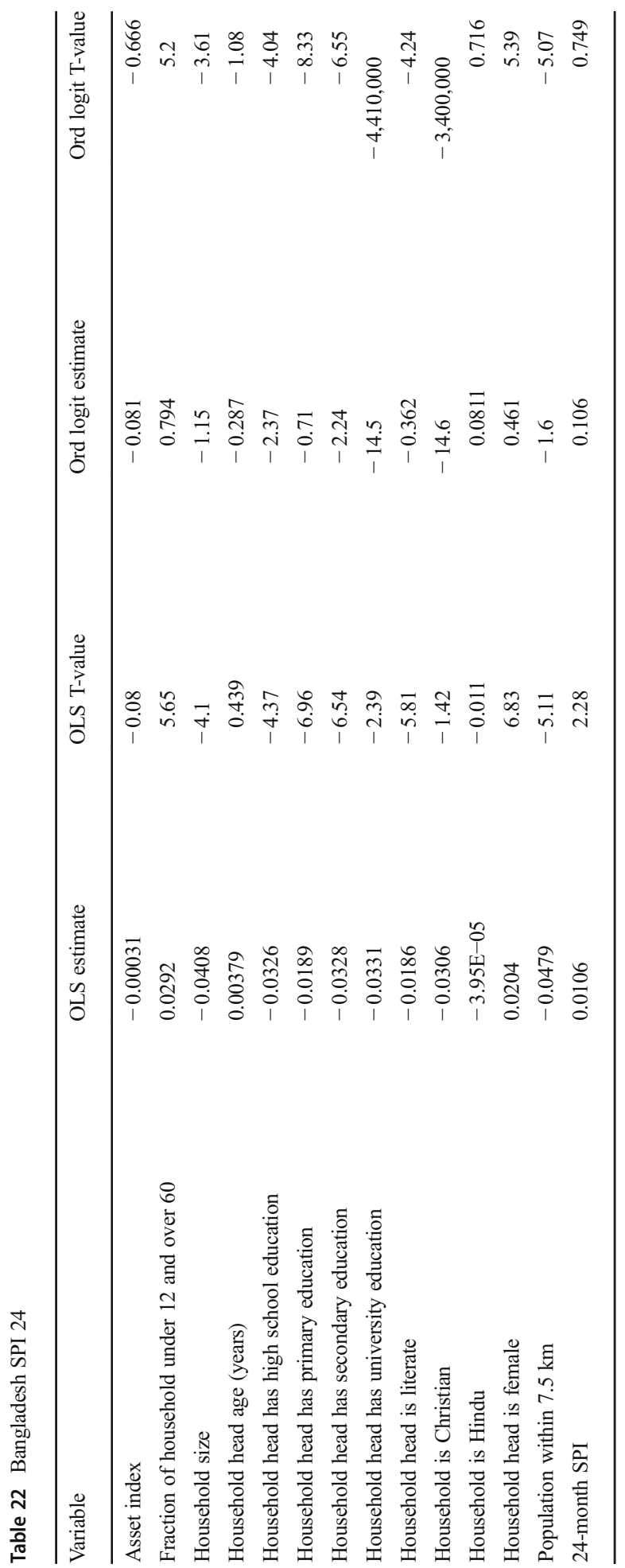




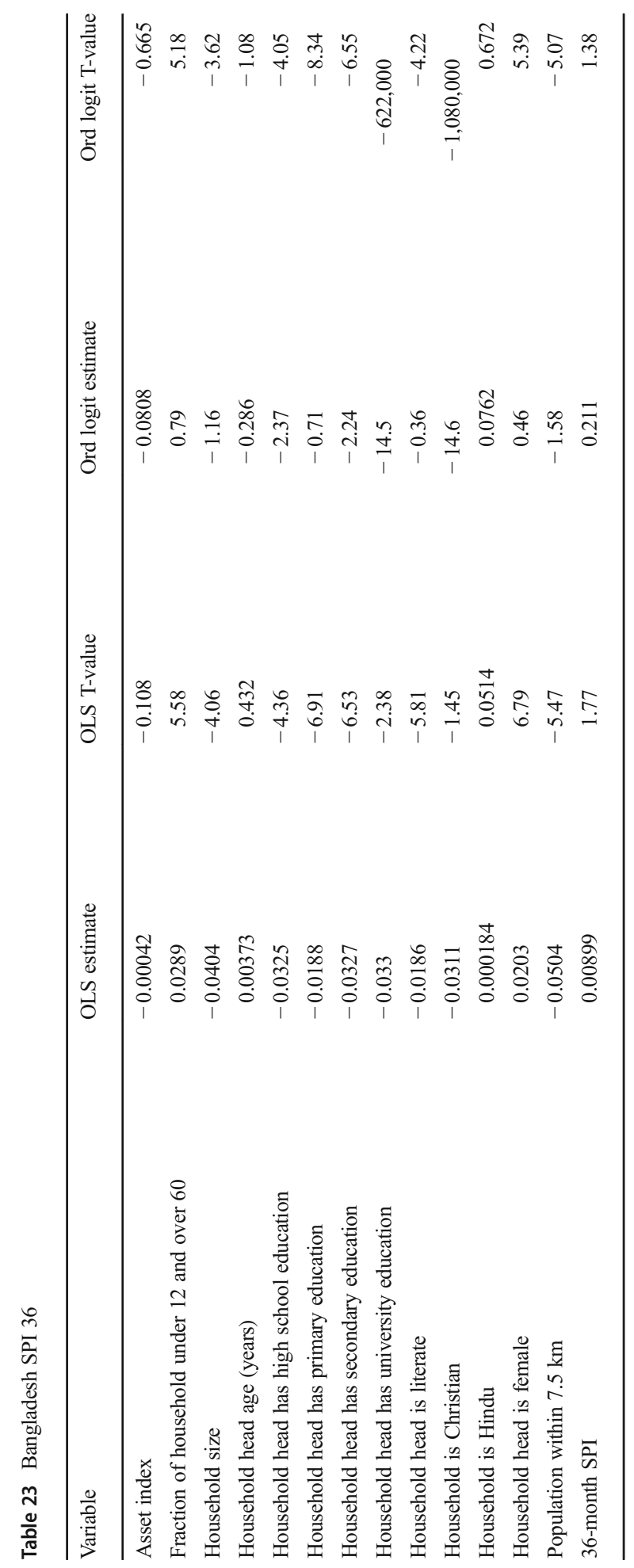




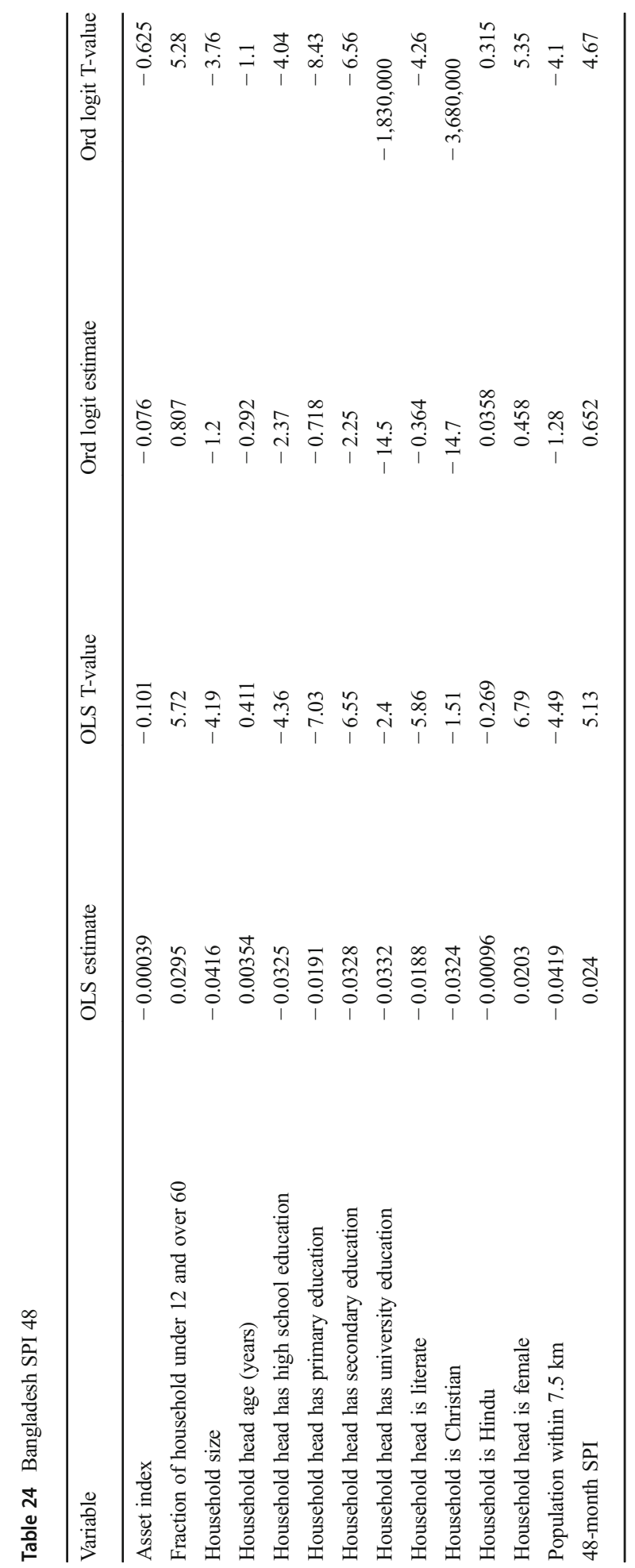




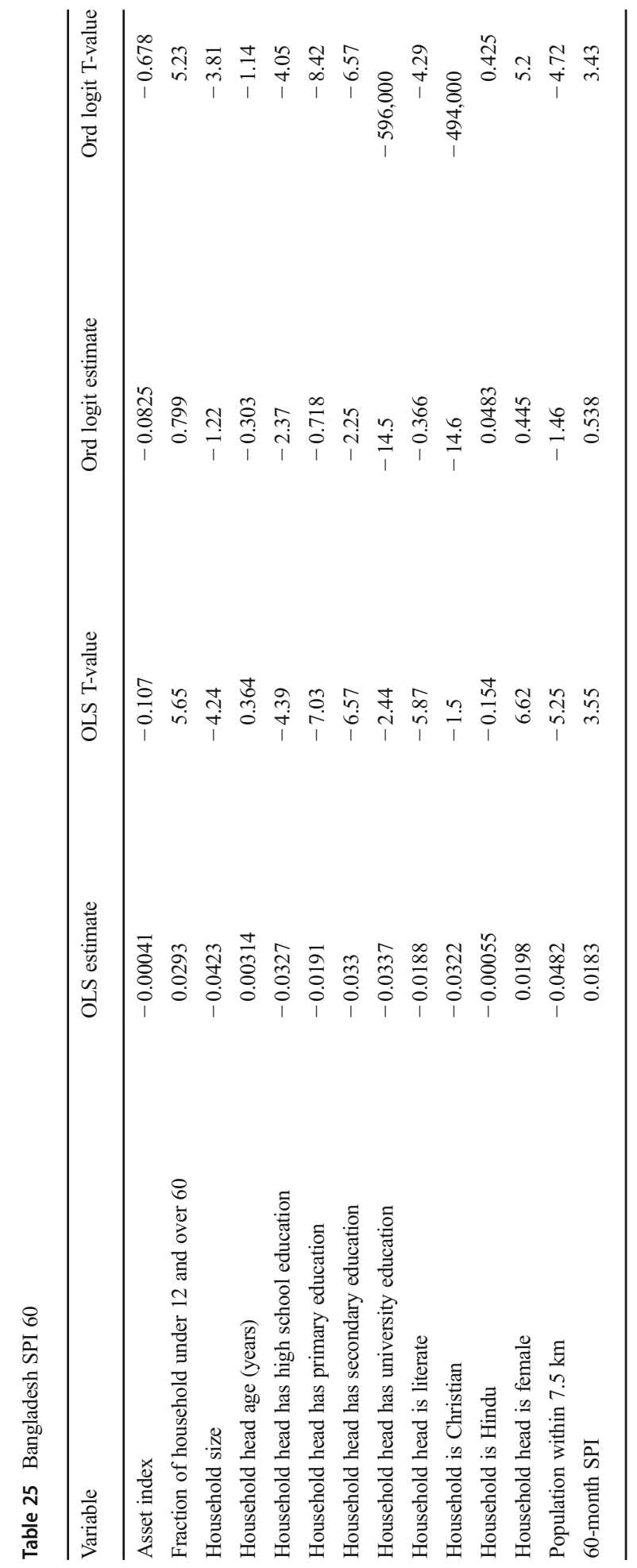


Open Access This article is distributed under the terms of the Creative Commons Attribution 4.0 International License (http://creativecommons.org/licenses/by/4.0/), which permits unrestricted use, distribution, and reproduction in any medium, provided you give appropriate credit to the original author(s) and the source, provide a link to the Creative Commons license, and indicate if changes were made.

\section{References}

Afifi, T., Liwenga, E., \& Kwezi, L. (2014). Rainfall-induced crop failure, food insecurity and out-migration in Same-Kilimanjaro, Tanzania. Climate and Development, 6(1), 53-60. https://doi.org/10.1080 /17565529.2013.826128.

Ahmed, A. S., Ahmed, T., Roy, S. K., Alam, N., \& Hossain, M. I. (2012). Determinants of undernutrition in children under 2 years of age from rural Bangladesh. Indian Pediatrics. https://doi.org/10.1007/s13312012-0187-2.

Akresh, R., Verwimp, P., \& Bundervoet, T. (2011). Civil war, crop failure, and child stunting in Rwanda. Economic Development and Cultural Change, 59(4), 777-810.

Akseer, N., Bhatti, Z., Mashal, T., Soofi, S., Moineddin, R., Black, R. E., \& Bhutta, Z. A. (2018). Geospatial inequalities and determinants of nutritional status among women and children in Afghanistan: An observational study. The Lancet Global Health. https://doi.org/10.1016/S2214-109X(18)30025-1.

Alam, K. (2015). Farmers' adaptation to water scarcity in drought-prone environments: A case study of Rajshahi District, Bangladesh. Agricultural Water Management. https://doi.org/10.1016/j. agwat.2014.10.011.

Alam, M. M., Toriman, B., M. E, Siwar, C., \& Talib, B. (2011). Rainfall variation and changing pattern of agricultural cycle. American Journal of Environmental Sciences. https://doi.org/10.3844 /ajessp.2011.82.89.

Alderman, H. (2010). Safety nets can help address the risks to nutrition from increasing climate variability. The Journal of Nutrition. https://doi.org/10.3945/jn.109.110825.

Alexander, M. J., Rashid, M. S., Shamsuddin, S. D., \& Alam, M. S. (1998). Flood control, drainage and irrigation projects in Bangladesh and their impact on soils: An empirical study. Land Degradation and Development. https://doi.org/10.1002/(SICI)1099-145X(199805/06)9:3<233::AID-LDR277>3.0.CO;2W.

Altieri, M. A., Funes-Monzote, F. R., \& Petersen, P. (2012). Agroecologically efficient agricultural systems for smallholder farmers: Contributions to food sovereignty. Agronomy for Sustainable Development. https://doi.org/10.1007/s13593-011-0065-6.

Altieri, M. A., \& Nicholls, C. I. (2017). The adaptation and mitigation potential of traditional agriculture in a changing climate. Climatic Change. https://doi.org/10.1007/s10584-013-0909-y.

Amikuzino, J., \& Donkoh, S. (2012). Climate variability and yields of major staple food crops in Northern Ghana. African Crop Science Journal.

Anselin, L. (2001). Spatial econometrics. A companion to theoretical econometrics. https://doi.org/10.1002 19780470996249.

Badham, J., \& Sweet, L. (2010). Stunting: An overview. Sight and Life Magazine, (no.3/2010), 40-47.

Ballard, T. (2011). Household hunger scale. Measurement, 23. http://www.fantaproject. org/downloads/pdfs/HHS_Indicator_Guide_Aug2011.pdf

Barrett, C. B., \& Santos, P. (2014). The impact of changing rainfall variability on resource-dependent wealth dynamics. Ecological Economics. https://doi.org/10.1016/j.ecolecon.2014.05.009.

Beguería, S., Vicente-Serrano, S. M., Reig, F., \& Latorre, B. (2014). Standardized precipitation evapotranspiration index (SPEI) revisited: Parameter fitting, evapotranspiration models, tools, datasets and drought monitoring. International Journal of Climatology. https://doi.org/10.1002/joc.3887.

Behrman, J. R. (2015). Growth faltering in the first thousand days after conception and catch-up growth. The Oxford handbook of economics and human biology.

Bezner Kerr, R., Berti, P. R., \& Shumba, L. (2011). Effects of a participatory agriculture and nutrition education project on child growth in northern Malawi. Public Health Nutrition. https://doi.org/10.1017 /S1368980010002545.

Bivand, R., Bernat, A., Carvalho, M., Chun, Y., Dormann, C. F., Dray, S., et al. (2005). The spdep package. Comprehensive R Archive Network, version 0.3-13. 
Black, R., Alderman, H., Bhutta, Z. A., Gillespie, S., Haddad, L., Horton, S., et al. (2013a). Maternal and child nutrition: Building momentum for impact. Lancet. https://doi.org/10.1016/S0140-6736(13)60988-5.

Black, R. E., Allen, L. H., Bhutta, Z. a., Caulfield, L. E., de Onis, M., Ezzati, M., et al. (2008). Maternal and child undernutrition: Global and regional exposures and health consequences. Lancet, 371(9608), 243260. https://doi.org/10.1016/S0140-6736(07)61690-0.

Black, R. E., Victora, C. G., Walker, S. P., Bhutta, Z. A., Christian, P., De Onis, M., et al. (2013b). Maternal and child undernutrition and overweight in low-income and middle-income countries. Lancet. https://doi. org/10.1016/S0140-6736(13)60937-X.

Bola, G., Mabiza, C., Goldin, J., Kujinga, K., Nhapi, I., Makurira, H., \& Mashauri, D. (2014). Coping with droughts and floods: A case study of Kanyemba, Mbire District, Zimbabwe. Physics and Chemistry of the Earth. https://doi.org/10.1016/j.pce.2013.09.019.

Briët, O. J. T., Vounatsou, P., Gunawardena, D. M., Galappaththy, G. N. L., \& Amerasinghe, P. H. (2008). Temporal correlation between malaria and rainfall in Sri Lanka. Malaria Journal. https://doi.org/10.1186 /1475-2875-7-77.

Brown, M. E. (2008). Famine early warning systems and remote sensing data. Famine Early Warning Systems and Remote Sensing Data. https://doi.org/10.1007/978-3-540-75369-8.

Brown, M. E., Grace, K., Shively, G., Johnson, K. B., \& Carroll, M. (2014). Using satellite remote sensing and household survey data to assess human health and nutrition response to environmental change. Population and Environment, 36(1), 48-72. https://doi.org/10.1007/s11111-013-0201-0.

Brown, M. E., \& Kshirsagar, V. (2015). Weather and international price shocks on food prices in the developing world. Global Environmental Change, 35, 31-40. https://doi.org/10.1016/j. gloenvcha.2015.08.003.

Buttenheim, A. M. (2008). The sanitation environment in urban slums: Implications for child health. Population and Environment. https://doi.org/10.1007/s11111-008-0074-9.

Calow, R. C., MacDonald, A. M., Nicol, A. L., \& Robins, N. S. (2010). Ground water security and drought in Africa: Linking availability, access, and demand. Ground Water. https://doi.org/10.1111/j.17456584.2009.00558.x

Carletto, C., Zezza, A., \& Banerjee, R. (2013). Towards better measurement of household food security: Harmonizing indicators and the role of household surveys. Global Food Security, 2(1), 30-40. https://doi. org/10.1016/j.gfs.2012.11.006.

Carlton, E. J., Eisenberg, J. N. S., Goldstick, J., Cevallos, W., Trostle, J., \& Levy, K. (2014). Heavy rainfall events and diarrhea incidence: The role of social and environmental factors. American Journal of Epidemiology. https://doi.org/10.1093/aje/kwt279.

Caulfield, L. E., Richard, S. A., Rivera, J. A., Musgrove, P., \& Black, R. E. (2006). Stunting, wasting, and micronutrient deficiency disorders. Disease Control Priorities in Developing Countries.

Chagomoka, T., Drescher, A., Glaser, R., Marschner, B., Schlesinger, J., Abizari, A. R., et al. (2018). Urban and peri-urban agriculture and its implication on food and nutrition insecurity in northern Ghana: A sociospatial analysis along the urban-rural continuum. Population and Environment. https://doi.org/10.1007 /s11111-018-0301-y.

Chotard, S., Mason, J. B., Oliphant, N. P., Mebrahtu, S., \& Hailey, P. (2011). Fluctuations in wasting in vulnerable child populations in the Greater Horn of Africa. Food and Nutrition Bulletin. https://doi. org/10.1177/15648265100313S302.

Coates, J., Webb, P., \& Houser, R. (2003). Measuring food insecurity: Going beyond indicators of income and anthropometry. Food and Nutrition Technical Assistance Project, Academy for Educational ....

Cornwell, K., \& Inder, B. (2015). Child health and rainfall in early life. Journal of Development Studies, 51(7), 865-880. https://doi.org/10.1080/00220388.2014.976618.

Cunguara, B., Langyintuo, A., \& Darnhofer, I. (2011). The role of nonfarm income in coping with the effects of drought in southern Mozambique. Agricultural Economics. https://doi.org/10.1111/j.15740862.2011.00542.x

Cunningham, K., Ruel, M., Ferguson, E., \& Uauy, R. (2015). Women's empowerment and child nutritional status in South Asia: A synthesis of the literature. Maternal \& Child Nutrition. https://doi.org/10.1111 /mcn. 12125 .

Daelmans, B., Darmstadt, G. L., Lombardi, J., Black, M. M., Britto, P. R., Lye, S., et al. (2017). Early childhood development: The foundation of sustainable development. Lancet. https://doi.org/10.1016 /S0140-6736(16)31659-2.

Deitchler, M., Ballard, T., Swindale, A., \& Coates, J. (2010). Validation of a measure of household hunger for cross-cultural use. DC: Washington. 
Del Ninno, C., Dorosh, P. A., \& Smith, L. C. (2003). Public policy, markets and household coping strategies in Bangladesh: Avoiding a food security crisis following the 1998 floods. World Development. https://doi. org/10.1016/S0305-750X(03)00071-8.

Delbiso, T. D., Rodriguez-Llanes, J. M., Donneau, A. F., Speybroeck, N., \& Guha-Sapir, D. (2017). Drought, conflict and children's undernutrition in Ethiopia 2000-2013: A meta-analysis. Bulletin of the World Health Organization. https://doi.org/10.2471/BLT.16.172700.

Delpla, I., Jung, A.-V., Baures, E., Clement, M., \& Thomas, O. (2009). Impacts of climate change on surface water quality in relation to drinking water production. Environment International. https://doi.org/10.1016 j.envint.2009.07.001.

Devereux, S. (2007). The impact of droughts and floods on food security and policy options to alleviate negative effects. In Agricultural Economics. https://doi.org/10.1111/j.1574-0862.2007.00234.x.

Dewey, K. G., \& Begum, K. (2011). Long-term consequences of stunting in early life. Maternal \& Child Nutrition, 7(SUPPL. 3), 5-18. https://doi.org/10.1111/j.1740-8709.2011.00349.x.

Di Falco, S., \& Chavas, J.-P. (2015). Rainfall shocks, resilience, and the effects of crop biodiversity on agroecosystem productivity. Land Economics. https://doi.org/10.3368/le.84.1.83.

Dinkelman, T. (2017). Long-run health repercussions of drought shocks: Evidence from South African homelands. Economic Journal. https://doi.org/10.1111/ecoj.12361.

Douglas, I. (2009). Climate change, flooding and food security in South Asia. Regional Environmental Change. https://doi.org/10.1038/nature09440.

Dowell, S. F. (2001). Seasonal variation in host susceptibility and cycles of certain infectious diseases. Emerging Infectious Diseases. https://doi.org/10.3201/eid0703.017301.

du Plessis, L. M., Naude, C. E., \& Swart, R. (2016). Nutrition during the first thousand days of life. Community Nutrition for Developing Countries, 65.

FAO, IFAD, UNICEFF, WFP, \& WHO. (2018). The state of food security and nutrition in the world 2018. Rome: Building climate resilience for food security and nutrition.

FAOSTAT. (2018). FAOSTAT. Food and Agricultural Organization of the United Nations.

Feed The Future. (2011). Feed the future: global food security research strategy. Framework, (May).

Funk, C. C., Verdin, J. P., Galu, G., Macharia, D., Shukla, S., Harrison, L., et al. (2016). Advancing integrated African early warning science and climate services. In AGU Fall Meeting Abstracts.

Funk, C., Dettinger, M. D., Michaelsen, J. C., Verdin, J. P., Brown, M. E., Barlow, M., \& Hoell, A. (2008). Warming of the Indian Ocean threatens eastern and southern African food security but could be mitigated by agricultural development. Proceedings of the National Academy of Sciences. https://doi.org/10.1073 /pnas.0708196105.

Funk, C., Peterson, P., Landsfeld, M., Pedreros, D., Verdin, J., Shukla, S., et al. (2015). The climate hazards infrared precipitation with stations-A new environmental record for monitoring extremes. Scientific Data, 2, 150066. https://doi.org/10.1038/sdata.2015.66.

Godoy, R., Nyberg, C., Eisenberg, D. T. A., Magvanjav, O., Shinnar, E., Leonard, W. R., et al. (2010). Short but catching up: Statural growth among native Amazonian Bolivian children. American Journal of Human Biology. https://doi.org/10.1002/ajhb.20996.

Grace, K., Davenport, F., Funk, C., \& Lerner, A. M. (2012). Child malnutrition and climate in sub-Saharan Africa : An analysis of recent trends in Kenya. Applied Geography, 35(1-2), 405-413. https://doi. org/10.1016/j.apgeog.2012.06.017.

Grace, K., Davenport, F., Hanson, H., Funk, C., \& Shukla, S. (2015). Linking climate change and health outcomes: Examining the relationship between temperature, precipitation and birth weight in Africa. Global Environmental Change. https://doi.org/10.1016/j.gloenvcha.2015.06.010.

Grace, K., Frederick, L., Brown, M. E., Boukerrou, L., \& Lloyd, B. (2017). Investigating important interactions between water and food security for child health in Burkina Faso. Population and Environment. https://doi.org/10.1007/s11111-017-0270-6.

Guo, Z., \& Cox, C. M. (2014). Market access. In Atlas of African agriculture research and development: Revealing agriculture's place in Africa. https://doi.org/10.2499/9780896298460 28.

Guttman, N. B. (1999). Accepting the standardized precipitation index: A calculation algorithm. Journal of the American Water Resources Association, 35(2), 311-322. https://doi.org/10.1111/j.1752-1688.1999. tb03592.x.

Haile, M. (2005). Weather patterns, food security and humanitarian response in sub-Saharan Africa. In Philosophical Transactions of the Royal Society B: Biological Sciences. https://doi.org/10.1098 /rstb.2005.1746.

Hanjra, M. A., \& Qureshi, M. E. (2010). Global water crisis and future food security in an era of climate change. Food Policy. https://doi.org/10.1016/j.foodpol.2010.05.006. 
Hashizume, M., Armstrong, B., Hajat, S., Wagatsuma, Y., Faruque, A. S. G., Hayashi, T., \& Sack, D. A. (2008). The effect of rainfall on the incidence of cholera in Bangladesh. Epidemiology. https://doi. org/10.1097/EDE.0b013e31815c09ea.

Huss-Ashmore, R., \& Curry, J. J. (1994). Diet, nutrition, and agricultural development in Swaziland. 3. Household economics and demography. Ecology of Food and Nutrition. https://doi.org/10.1080 /03670244.1994.9991419.

Hyland, M., \& Russ, J. (2019). Water as destiny - The long-term impacts of drought in sub-Saharan Africa. World Development. https://doi.org/10.1016/j.worlddev.2018.11.002.

IFPRI. (2016). Global nutrition report 2016: From promise to impact: Ending malnutrition by 2030. Washington, DC. https://doi.org/10.2499/9780896295841.

IPC/FAO. (2015). Integrated food security phase classification. Food and Agriculture Organization. https://doi.org/10.1016/j.cca.2006.07.024.

IPCC. (2013). IPCC fifth assessment report (AR5). IPCC, $s, 10-12$.

Jones, A. D., Ngure, F. M., Pelto, G., \& Young, S. L. (2013). What are we assessing when we measure food security? A compendium and review of current metrics. Advances in Nutrition: An International Review Journal, 4(5), 481-505. https://doi.org/10.3945/an.113.004119.

Kazianga, H., \& Udry, C. (2006). Consumption smoothing? Livestock, insurance and drought in rural Burkina Faso. Journal of Development Economics. https://doi.org/10.1016/j.jdeveco.2006.01.011.

Lay, J., Narloch, U., \& Mahmoud, T. O. (2009). Shocks, structural change, and the patterns of income diversification in Burkina Faso. In African Development Review. https://doi.org/10.1111/j.14678268.2009.00202.x.

Lazzaroni, S., \& Wagner, N. (2016). Misfortunes never come singly: Structural change, multiple shocks and child malnutrition in rural Senegal. Economics and Human Biology. https://doi.org/10.1016/j. ehb.2016.10.006.

Lewit, E. M., \& Kerrebrock, N. (1997). Population-based growth stunting. The Future of Children. https://doi. org/10.2307/1602393.

Lobell, D. B., Burke, M. B., Tebaldi, C., Mastrandrea, M. D., Falcon, W. P., \& Naylor, R. L. (2008). Prioritizing climate change adaptation needs for food security in 2030. Science, 319(5863), 607-610. https://doi.org/10.1126/science.1152339.

Lopez-Carr, D., Mwenda, K. M., Pricope, N. G., Kyriakidis, P. C., Jankowska, M. M., Weeks, J., et al. (2016). Climate-related child undernutrition in the Lake Victoria basin: An integrated spatial analysis of health surveys, ndvi, and precipitation data. IEEE Journal of Selected Topics in Applied Earth Observations and Remote Sensing, 9(6), 2830-2835. https://doi.org/10.1109/JSTARS.2016.2569411.

Maccini, S., \& Yang, D. (2009). Under the weather: Health, schooling, and economic consequences of earlylife rainfall. The American Economic Review, 99(3), 1006-1026. https://doi.org/10.1257/aer.99.3.1006.

Maxwell, D. (2002). Adaptable livelihoods. Coping with food insecurity in the Malian Sahel. Food Policy. https://oi.org/10.1016/s0306-9192(97)88089-x.

Maxwell, S. (1996). Food security: A post-modern perspective. Food Policy, 21(2), 155-170. https://doi. org/10.1016/0306-9192(95)00074-7.

McCreesh, N., Nikulin, G., \& Booth, M. (2015). Predicting the effects of climate change on Schistosoma mansoni transmission in eastern Africa. Parasites \& Vectors. https://doi.org/10.1186/s13071-014-0617-0.

Mirza, M. M. Q. (2011). Climate change, flooding in South Asia and implications. Regional Environmental Change. https://doi.org/10.1007/s10113-010-0184-7.

Monirul Qader Mirza, M. (2002). Global warming and changes in the probability of occurrence of floods in Bangladesh and implications. Global Environmental Change. https://doi.org/10.1016/S0959-3780(02 )00002-X.

Moore, S. M., Azman, A. S., Zaitchik, B. F., Mintz, E. D., Brunkard, J., Legros, D., et al. (2017). El Niño and the shifting geography of cholera in Africa. Proceedings of the National Academy of Sciences. https://doi. org/10.1073/pnas.1617218114.

Morton, J. F. (2007). The impact of climate change on smallholder and subsistence agriculture. Proceedings of the National Academy of Sciences. https://doi.org/10.1073/pnas.0701855104.

Mulmi, P., Block, S. A., Shively, G. E., \& Masters, W. A. (2016). Climatic conditions and child height: Sexspecific vulnerability and the protective effects of sanitation and food markets in Nepal. Economics and Human Biology. https://doi.org/10.1016/j.ehb.2016.07.002.

Odongo-Aginya, E., Ssegwanyi, G., Kategere, P., \& Vuzi, P. C. (2005). Relationship between malaria infection intensity and rainfall pattern in Entebbe peninsula, Uganda, African Health Sciences doi: https://doi.org/10.5555/afhs.2005.5.3.238. 
Pandey, S., Bhandari, H., Ding, S., Prapertchob, P., Sharan, R., Naik, D., et al. (2007). Coping with drought in rice farming in Asia: Insights from a cross-country comparative study. In Agricultural Economics. https://doi.org/10.1111/j.1574-0862.2007.00246.x.

Paterson, R. R. M., \& Lima, N. (2010). How will climate change affect mycotoxins in food? Food Research International. https://doi.org/10.1016/j.foodres.2009.07.010.

Patton, B. D., Dong, X., Nyren, P. E., \& Nyren, A. (2007). Effects of grazing intensity, precipitation, and temperature on forage production. Rangeland Ecology \& Management. https://doi.org/10.2111/07-008 R2.1.

Patz, J. A., Campbell-Lendrum, D., Holloway, T., \& Foley, J. A. (2005). Impact of regional climate change on human health. Nature. https://doi.org/10.1038/nature04188.

Patz, J. A., Daszak, P., Tabor, G. M., Aguirre, A. A., Pearl, M., Epstein, J., et al. (2004). Unhealthy landscapes: Policy recommendations on land use change and infectious disease emergence. Environmental Health Perspectives. https://doi.org/10.1289/ehp.6877.

Perumal, N., Bassani, D. G., \& Roth, D. E. (2018). Use and misuse of stunting as a measure of child health. The Journal of Nutrition, 148(3), 311-315. https://doi.org/10.1093/jn/nxx064.

Phalkey, R. K., Aranda-Jan, C., Marx, S., Höfle, B., \& Sauerborn, R. (2015). Systematic review of current efforts to quantify the impacts of climate change on undernutrition. Proceedings of the National Academy of Sciences, 112(33), E4522-E4529. https://doi.org/10.1073/pnas.1409769112.

Raso, G., Vounatsou, P., Singer, B. H., N'Goran, E. K., Tanner, M., \& Utzinger, J. (2006). An integrated approach for risk profiling and spatial prediction of Schistosoma mansoni-hookworm coinfection. Proceedings of the National Academy of Sciences. https://doi.org/10.1073/pnas.0601559103.

Rodriguez-Llanes, J. M., Ranjan-Dash, S., Degomme, O., Mukhopadhyay, A., \& Guha-Sapir, D. (2011). Child malnutrition and recurrent flooding in rural eastern India: A community-based survey. BMJ Open, 1(2). https://doi.org/10.1136/bmjopen-2011-000109.

Schlenker, W., \& Lobell, D. B. (2010). Robust negative impacts of climate change on African agriculture. Environmental Research Letters, 5(1). https://doi.org/10.1088/1748-9326/5/1/014010.

Scoones, I. (1998). Sustainable rural livelihoods: A framework for analysis. Institute of Development Studies. https://doi.org/10.1057/palgrave.development.1110037.

Sen, A. (1983). Poverty and famine: An essay on entitlement and deprivation. Journal of Comparative Economics. https://doi.org/10.1016/0147-5967(83)90075-6.

Sheffield, J., Goteti, G., \& Wood, E. F. (2006). Development of a 50-year high-resolution global dataset of meteorological forcings for land surface modeling. Journal of Climate, 19(13), 3088-3111. https://doi. org/10.1175/JCLI3790.1.

Shively, G. E. (2017). Infrastructure mitigates the sensitivity of child growth to local agriculture and rainfall in Nepal and Uganda. Proceedings of the National Academy of Sciences, 114(5). https://doi.org/10.1073 /pnas.1524482114.

Siebert, S., Döll, P., Feick, S., Frenken, K., Hoogeveen, J. (2013). Global map of irrigation areas version 5. University of Frankfurt (Main), Germany, and FAO, Rome, Italy. https://doi.org/10.13140/2.1.2660.6728.

Skoufias, E., \& Vinha, K. (2012). Climate variability and child height in rural Mexico. Economics and Human Biology. https://doi.org/10.1016/j.ehb.2011.06.001.

Stifel, D., \& Minten, B. (2008). Isolation and agricultural productivity. Agricultural Economics. https://doi. org/10.1111/j.1574-0862.2008.00310.x.

Stobaugh, H. C., Rogers, B. L., Rosenberg, I. H., Webb, P., Maleta, K. M., Manary, M. J., \& Trehan, I. (2018). Children with poor linear growth are at risk for repeated relapse to wasting after recovery from moderate acute malnutrition. The Journal of Nutrition. https://doi.org/10.1093/jn/nxy033.

Tatem, A. J. (2017). WorldPop, open data for spatial demography. Scientific Data, 4, 170004. https://doi. org/10.1038/sdata.2017.4.

Tefera, T. (2012). Post-harvest losses in African maize in the face of increasing food shortage. Food Security. https://doi.org/10.1007/s12571-012-0182-3.

Thapa, G., \& Shively, G. (2018). A dose-response model of road development and child nutrition in Nepal. Research in Transportation Economics. https://doi.org/10.1016/j.retrec.2018.11.002.

The World Bank. (2019). World Bank Open Data. https://data.worldbank.org/. Accessed 12 February 2019.

Thomson, M. C., Mason, S. J., Phindela, T., \& Connor, S. J. (2005). Use of rainfall and sea surface temperature monitoring for malaria early warning in Botswana. The American Journal of Tropical Medicine and Hygiene. https://doi.org/10.4269/ajtmh.2005.73.214.

Thornton, P. K., Jones, P. G., Alagarswamy, G., \& Andresen, J. (2009). Spatial variation of crop yield response to climate change in East Africa. Global Environmental Change, 19(1), 54-65. https://doi.org/10.1016/j. gloenvcha.2008.08.005. 
Udmale, P. D., Ichikawa, Y., Manandhar, S., Ishidaira, H., Kiem, A. S., Shaowei, N., \& Panda, S. N. (2015). How did the 2012 drought affect rural livelihoods in vulnerable areas? Empirical evidence from India. International Journal of Disaster Risk Reduction. https://doi.org/10.1016/j.ijdrr.2015.08.002.

Vaitla, B., Coates, J., Glaeser, L., Hillbruner, C., Biswal, P., \& Maxwell, D. (2017). The measurement of household food security: Correlation and latent variable analysis of alternative indicators in a large multicountry dataset. Food Policy. https://doi.org/10.1016/j.foodpol.2017.02.006.

Vyas, S., \& Kumaranayake, L. (2006). Constructing socio-economic status indices: How to use principal components analysis. Health Policy and Planning, 21(6), 459-468. https://doi.org/10.1093 /heapol/czl029.

Ward, M. D., \& Gleditsch, K. S. S. (2008). Spatial regression models. Quantitative Applications in the Social Sciences, 155, 77-87 http://books.google.com/books?id=jbFRojt85TUC.

WBG. (2016). World Bank Group Climate Change Action plan 2016-2020. World Bank Group. https://doi. org/10.1111/1467-8322.12302.

Webb, P. (2010). Medium- to long-run implications of high food prices for global nutrition. The Journal of Nutrition. https://doi.org/10.3945/jn.109.110536.

Webb, P., \& Kennedy, E. (2014). Impacts of agriculture on nutrition: Nature of the evidence and research gaps. Food and Nutrition Bulletin. https://doi.org/10.1177/156482651403500113.

WHO. (1995). Physical status: The use and interpretation of anthropometry. World Health Organization Technical Report Series. doi:854.

Wilhite, D. A., Sivakumar, M. V. K., \& Pulwarty, R. (2014). Managing drought risk in a changing climate: The role of national drought policy. Weather and Climate Extremes. https://doi.org/10.1016/j. wace.2014.01.002.

Wit, J., \& Boersma, B. (2002). Catch-up growth: Definition, mechanisms, and models. JPEM: Journal of pediatric endocrinology \& metabolism.

Woldehanna, T., \& Lives, Y. (2010). Do pre-natal and post-natal economic shocks have a long-lasting effect on the height of 5-year-old children?: Evidence from 20 sentinel sites of rural and urban Ethiopia. Young Lives: Department of International Development, University of Oxford.

Wooldrige, J. M. (2013). The chow test for structural change across time. In Introdocutory Econometrics (5th ed., pp. 453-454). Cengage Learning.

You, L., Wood-Sichra, U., Fritz, S., Guo, Z., See, L., \& Koo, J. (2014). Spatial Production Allocation Model (SPAM), 2005, v2.0.

Publisher's note Springer Nature remains neutral with regard to jurisdictional claims in published maps and institutional affiliations. 